\title{
The Origin and Fate of Organic Pollutants from the Combustion of Alternative Fuels
}

University of Dayton Research Institute Dayton, $\mathrm{OH}$

NREL technical monitor:

B. Bailey

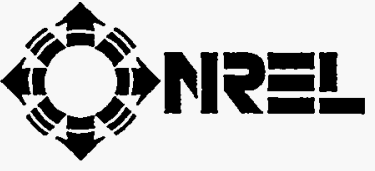

National Renewable Energy Laboratory 1617 Cole Boulevard Golden, Colorado 80401-3393

A national laboratory of the U.S. Department of Energy Managed by Midwest Research Institute for the U.S. Department of Energy Under Contract No. DE-AC36-83CH10093

Prepared under Subcontract Number XAU-3-12228-02

June 1995 
This publication was reproduced from the best available camera-ready copy submitted by the subcontractor and received no editorial review at NREL.

\section{NOTICE}

This report was prepared as an account of work sponsored by an agency of the United States government. Neither the United States government nor any agency thereof, nor any of their employees, makes any warranty, express or implied, or assumes any legal liability or responsibility for the accuracy, completeness, or usefulness of any information, apparatus, product, or process disclosed, or represents that its use would not infringe privately owned rights. Reference herein to any specific commercial product, process, or service by trade name, trademark, manufacturer, or otherwise does not necessarily constitute or imply its endorsement recommendation, or favoring by the Unitecl States government or any agency thereof. The views and opinions' of authors expressed herein do not necessarily state or reflect those of the United States government or any agency thereof.

Available to DOE and DOE contractors from: Office of Scientific and Technical Information (OSTI) P.O. Box 62

Oak Ridge, TN 37831

Prices available by calling (615) 576-8401

Available to the public from:

National Technical Information Service (NTIS)

U.S. Department of Commerce

5285 Port Royal Road

Springfield, VA 22161

(703) $487-4650$ 


\section{DISCLAIMER}

Portions of this document may be illegible in electronic image products. Images are produced from the best available original document. 


\section{Phase II Executive Summary}

The overall objective of this project is to determine the impact of alternative fuels on air quality, particularly ozone formation. This objective will be met through three steps: (1) qualitative identification of alternative fuel combustion products; (2) quantitative measurement of specific emission levels of these products; and (3) determination of the fate of the combustion products in the atmosphere, particularly in terms of depletion or conversion by hydroxyl $(\mathrm{OH})$ radical attack. The alternative fuels of interest are methanol, ethanol, natural gas, and liquefied petroleum (LP) gas.

The role of the University of Dayton Research Institute (UDRI) in this project is twofold. First, fused silica flow reactor instrumentation is being used to obtain both qualitative identification and quantitative emissions data on the thermal degradation products from the fuel-lean (oxidative), stoichiometric, and fuel-rich (pyrolytic) decomposition of methanol, ethanol, natural gas, and LP gas. Second, a laser photolysis/laser-induced fluorescence apparatus is being used to determine the rates and mechanisms of reaction of selected degradation products under atmospheric conditions.

In the second year of this study, we have completed the thermal degradation studies of the fuel-lean (oxidative), stoichiometric, and fuel-rich (pyrolytic) decomposition of methanol, ethanol, natural gas, and LP gas. We have also obtained rate measurements of the reaction of hydroxyl radical (OH) with methanol and ethanol over an extended temperature range. The most important findings are summarized below.

Flow reactor studies indicated the following general trend in non-methane hydrocarbon (NMHC) emissions: methanol < ethanol $\leq$ natural gas < LP gas. The same data indicated the following general trend in total oxygenate emissions: natural gas $\cong$ LP gas $\cong$ methanol $<$ ethanol. Indicated specific reactivities (ISR), a measure of the atmospheric reactivity of the organic byproducts, were calculated from the quantified byproduct yields and produced a more complex trend. At relatively low temperatures, e.g. $750^{\circ} \mathrm{C}$, the following trend was observed: methanol < natural gas < LP gas $\leq$ ethanol. However, at higher temperatures, e.g. $1000^{\circ} \mathrm{C}$, the ISRs for natural gas, LP gas, and ethanol decreased markedly due to the reduced emission of olefinic hydrocarbons and acetaldehyde. As a result, the ISRs for all four fuels were essentially zero.

Organic speciation was found to depend on fuel type, which has been only recently concluded for the various components of conventional gasoline. A qualitative comparison of non-methane organic gases (NMOG) quantified in the flow reactor tests versus the recent engine tests performed by Southwest Research Institute was conducted. The quantified emission byproducts for the methanol and ethanol were remarkably similar. The most significant differences in the comparisons were the lack of detection of the "air toxics" acetaldehyde, benzene, and 1,3butadiene from the flow reactor studies of methanol degradation and the lack of detection of 1,3butadiene from the flow reactor studies of ethanol degradation. The quantified emission byproducts for the gaseous, hydrocarbon fuels were also quite similar. The flow reactor studies indicated significant formation of heavier hydrocarbons, particularly under oxygen-free pyrolysis conditions. These products, excluding benzene, toluene, and ethyl benzene, were not observed in the engine tests. Another notable difference was the detection of formaldehyde from the engine tests. Formaldehyde was not observed in the flow reactor experiments, although trace formation of acetaldehyde and 2-propenal was observed. A quantitative comparison of major NMOG species was also conducted. Flow reactor tests of natural gas and LP gas oxidation at $750^{\circ} \mathrm{C}$ provided the best overall agreement with engine tests. The best agreement for methanol and ethanol required lower flow reactor temperatures $\left(600^{\circ} \mathrm{C}\right.$ and $500^{\circ} \mathrm{C}$, respectively). 


\section{Table of Contents}

\begin{tabular}{|c|c|c|c|c|c|c|c|c|c|c|c|c|c|c|c|c|c|c|c|c|}
\hline \multicolumn{4}{|c|}{ Phase II Executive Summary } & & - & & - & & - & & - & & . & 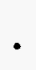 & • & - & - & - & - & $\mathrm{i}$ \\
\hline List of Figures & & $\cdot$ & - & & . & & . & & & & 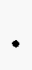 & & $\bullet$ & $\bullet$ & - & - & - & . & . & \\
\hline List of Tables & & • & . & & 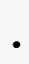 & & . & & & & & & & & . & . & . & - & . & i \\
\hline Introduction & & - & - & & & & & & & & & & & & . & . & . & . & . & \\
\hline Task 1-High Te & & ture & Flo & & & & & & & & & & & & Alt & nat & ve & iue & & \\
\hline Experiment & & roac & & & & & & & & & & & 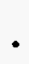 & • & $\cdot$ & . & - & • & . & \\
\hline Results & & • & . & & & & 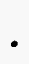 & & $\bullet$ & & $\bullet$ & & & 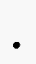 & . & . & . & . & . & \\
\hline Discussion & & . & . & & & & & & & & & & & & . & . & • & . & . & 16 \\
\hline $\begin{array}{l}\text { Task 2-Elemen } \\
\text { Temperatur }\end{array}$ & & eti & ion & & & & & & & & & & & & cts & ove & . & Ext & - & 2 \\
\hline Experiment & & roac & & & & & 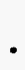 & & & • & 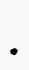 & & $\bullet$ & $\bullet$ & • & • & • & & - & 25 \\
\hline Results & - & $\cdot$ & $\cdot$ & & ${ }^{\circ}$ & & 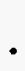 & & & & & & 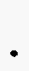 & & • & • & • & 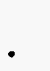 & - & 28 \\
\hline Discussion & & . & . & & 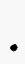 & & & & & & & & & & . & • & $\cdot$ & • & • & 31 \\
\hline References & & . & . & & & & & & & & & & & & . & . & . & . & . & 3 \\
\hline
\end{tabular}




\section{List of Figures}

Page

1. Block diagram of thermal decomposition analytical system. . . . . . . 2

2. Schematic of the helical, fused silica flow reactor . . . . . . . . 3

3. Schematic of time/temperature history of sample injection, high-temperature thermal exposure, and downstream quenching and separation of reaction byproducts. . . 3

4. Organic byproduct distributions from the thermal degradation of methanol.

$\phi=1.0 . \mathrm{t}_{\mathrm{r}}=2.0 \mathrm{~s} .\left[\mathrm{CH}_{3} \mathrm{OH}\right]_{0}=1230 \mathrm{ppm}$.

5. Total ion chromatogram of the thermal degradation of methanol. a) $\phi=1.0, T_{\mathrm{I}}=800^{\circ} \mathrm{C}$, $\mathrm{t}_{\mathrm{r}}=1.1 \mathrm{sec} .\left[\mathrm{CH}_{3} \mathrm{OH}\right]_{0}=1760 \mathrm{ppm}$. b) Pyrolysis, $\mathrm{T}_{\mathrm{r}}=1050^{\circ} \mathrm{C}, \mathrm{t}_{\mathrm{r}}=0.9 \mathrm{sec}$, $\left[\mathrm{CH}_{3} \mathrm{OH}\right]_{0}=1760 \mathrm{ppm}$.

6. Organic byproduct distributions from the thermal degradation of ethanol. $\phi=1.0 . \mathrm{t}_{\mathrm{r}}=2.0 \mathrm{~s} .\left[\mathrm{CH}_{3} \mathrm{CH}_{2} \mathrm{OH}\right]_{0}=640 \mathrm{ppm}$.

7. Total ion chromatogram of the thermal degradation of ethanol. a) $\phi=1.0, T_{\mathrm{r}}=800^{\circ} \mathrm{C}$, $t_{\mathrm{r}}=1.1 \mathrm{sec}$. $\left[\mathrm{CH}_{3} \mathrm{CH}_{2} \mathrm{OH}\right]_{0}=640 \mathrm{ppm}$. b) Pyrolysis, $\mathrm{T}_{\mathrm{r}}=1050^{\circ} \mathrm{C}, \mathrm{t}_{\mathrm{r}}=0.9 \mathrm{sec}$, $\left[\mathrm{CH}_{3} \mathrm{CH}_{2} \mathrm{OH}\right]_{0}=980 \mathrm{ppm}$.

8. Organic byproduct distributions from the thermal degradation of natural gas. $\phi=1.0 . \mathrm{t}_{\mathrm{r}}=2.0 \mathrm{~s} .\left[\mathrm{CH}_{4}\right]_{0}=680 \mathrm{ppm} .\left[\mathrm{C}_{2} \mathrm{H}_{6}\right]_{0}=50 \mathrm{ppm} .\left[\mathrm{C}_{3} \mathrm{H}_{8}\right]_{0}=25 \mathrm{ppm}$. The initial concentrations of butane, pentane, and hexane were less than $15 \mathrm{ppm}$

9. Organic byproduct distributions $\left(\leq C_{3}\right)$ from the pyrolytic thermal degradation of natural gas. $\mathrm{t}_{\mathrm{r}}=2.0 \mathrm{~s}$. $\left[\mathrm{CH}_{4}\right]_{0}=1120 \mathrm{ppm}$. $\left[\mathrm{C}_{2} \mathrm{H}_{6}\right]_{0}=85 \mathrm{ppm}$. $\left[\mathrm{C}_{3} \mathrm{H}_{8}\right]_{0}=40 \mathrm{ppm}$. The initial concentrations of butane, pentane, and hexane were less than $25 \mathrm{ppm}$. . 11

10. Organic byproduct distributions $\left(>\mathrm{C}_{3}\right)$ from the pyrolytic thermal degradation of natural gas. $t_{r}=2.0 \mathrm{~s}$. $\left[\mathrm{CH}_{4}\right]_{0}=1120 \mathrm{ppm}$. $\left[\mathrm{C}_{2} \mathrm{H}_{6}\right]_{0}=85 \mathrm{ppm} .\left[\mathrm{C}_{3} \mathrm{H}_{8}\right]_{0}=40 \mathrm{ppm}$. The initial concentrations of butane, pentane, and hexane were less than $25 \mathrm{ppm}$. $\quad .11$

11. Total ion chromatogram of the thermal degradation of natural gas. a) $\phi=1.0, \mathrm{~T}_{\mathrm{I}}=800^{\circ} \mathrm{C}$, $t_{r}=1.1$ sec. b) Pyrolysis, $T_{r}=1050^{\circ} \mathrm{C}, t_{r}=0.9$ sec. See Table 3 for initial concentrations.

12. Organic byproduct distributions from the thermal degradation of LP gas. $\phi=1.0$. $\mathrm{t}_{\mathrm{r}}=2.0 \mathrm{~s}$. $\left[\mathrm{C}_{3} \mathrm{H}_{8}\right]_{0}=815 \mathrm{ppm}$. $\left[\mathrm{C}_{2} \mathrm{H}_{6}\right]_{0}=18 \mathrm{ppm} .\left[\mathrm{C}_{3} \mathrm{H}_{6}\right]_{0}=54 \mathrm{ppm}$. The initial concentrations of butane and heavier hydrocarbons were less than $5 \mathrm{ppm}$. . .

13. Organic byproduct distributions $\left(\mathrm{SC}_{4}\right)$ from the pyrolytic thermal degradation of LP gas. $\mathrm{t}_{\mathrm{r}}=2.0 \mathrm{~s}$. $\left[\mathrm{C}_{3} \mathrm{H}_{8}\right]_{0}=1180 \mathrm{ppm} .\left[\mathrm{C}_{2} \mathrm{H}_{6}\right]_{0}=25 \mathrm{ppm}$. $\left[\mathrm{C}_{3} \mathrm{H}_{6}\right]_{0}=80 \mathrm{ppm}$. The initial concentrations of butane and heavier hydrocarbons were less than $5 \mathrm{ppm}$.

14. Organic byproduct distributions $\left(\mathrm{CC}_{4}\right)$ from the pyrolytic thermal degradation of. LP gas. $\mathrm{t}_{\mathrm{r}}=2.0 \mathrm{~s}$. $\left[\mathrm{C}_{3} \mathrm{H}_{8}\right]_{0}=1180 \mathrm{ppm}$. $\left[\mathrm{C}_{2} \mathrm{H}_{6}\right]_{0}=25 \mathrm{ppm}$. $\left[\mathrm{C}_{3} \mathrm{H}_{6}\right]_{0}=80 \mathrm{ppm}$. The initial concentrations of butane and heavier hydrocarbons were less than $5 \mathrm{ppm}$. 


\section{List of Figures \\ (continued)}

15. Total ion chromatogram of the thermal degradation of $L P$ gas. a) $\phi=1.0, T_{r}=800^{\circ} \mathrm{C}$, $t_{r}=1.1$ sec. b) Pyrolysis, $T_{r}=1050^{\circ} \mathrm{C}, t_{r}=0.9$ sec. See Table 3 for initial

concentrations.

16. Yields of non-methane hydrocarbons (NMHCs) expressed as $\mathrm{C}_{1}$ 's from methanol, ethanol, natural gas, and LP gas as a function of equivalence ratio. $T_{r}=750^{\circ} \mathrm{C}$. $\mathrm{t}_{\mathrm{r}}=2.0 \mathrm{sec}$. Initial fuel concentration: see Table 3 .

17. Yields of non-methane hydrocarbons (NMHCs) expressed as $C_{1}$ 's from methanol, ethanol, natural gas, and LP gas as a function of equivalence ratio. $T_{r}=1000^{\circ} \mathrm{C}$. $\mathrm{t}_{\mathrm{r}}=2.0 \mathrm{sec}$. Initial fuel concentration: see Table $3 . . . \quad . \quad . \quad . \quad$.

18. Yields of total oxygenates (mole fraction) from methanol, ethanol, natural gas, and LP gas as a function of equivalence ratio. ${ }^{-} T_{r}=750^{\circ} \mathrm{C} . t_{r}=2.0 \mathrm{sec}$. Initial fuel concentration: see Table 3.

19. Normalized, semi-quantitative organic byproduct distributions as a function of fuel type. $\phi=1, T_{r}=800^{\circ} \mathrm{C}, t_{r}=1.0 \pm 0.1 \mathrm{sec}$. For initial fuel concentration, see Table 3 .

20. Normalized, semi-quantitative organic byproduct distributions as a function of fuel type. Pyrolysis, $T_{\mathrm{r}}=800^{\circ} \mathrm{C}, \mathrm{t}_{\mathrm{r}}=1.0 \pm 0.1 \mathrm{sec}$. For initial fuel concentration, see Table 3 .

21. Indicated specific reactivity (ISR) determinations for methanol, ethanol, natural gas, and LP gas as a function of equivalence ratio. $T_{r}=750^{\circ} \mathrm{C} . \mathrm{t}_{\mathrm{r}}=2.0 \mathrm{sec}$. Initial fuel concentration: see Table 3 .

22. Indicated specific reactivity (ISR) determinations for methanol, ethanol, natural gas, and LP gas as a function of equivalence ratio. $T_{\mathrm{r}}=1000^{\circ} \mathrm{C}$. $\mathrm{t}_{\mathrm{r}}=2.0 \mathrm{sec}$. Initial fuel concentration: see Table 3 .

23. Comparison of NMOG byproduct distributions from SWRI engine tests ${ }^{2}$ and UDRI flow reactor experiments. Engine data are engine out, no catalyst emissions. Flow reactor data were obtained for the following conditions: Methanol, $\phi=1, \mathrm{~T}_{\mathrm{r}}=600^{\circ} \mathrm{C}, \mathrm{t}_{\mathrm{r}}=2.0 \mathrm{sec}$; Ethanol, $\phi=1, \mathrm{~T}_{\mathrm{I}}=500^{\circ} \mathrm{C}, \mathrm{t}_{\mathrm{I}}=2.0 \mathrm{sec}$. See Table 3 for initial fuel concentrations.

24. Comparison of NMOG byproduct distributions from SWRI engine tests ${ }^{2}$ and UDRI flow reactor experiments. Engine data are engine out, no catalyst emissions. Flow reactor data were obtained for the following conditions: Natural gas, $\phi=1, T_{\Gamma}=750^{\circ} \mathrm{C}, \mathrm{t}_{\mathrm{T}}=2.0 \mathrm{sec}$; LP gas, $\phi=1, T_{r}=750^{\circ} \mathrm{C}, t_{T}=2.0 \mathrm{sec}$. See Table 3 for initial fuel concentrations.

25. Schematic of OH LP/LIF system (left) and high temperature optical test cell (right).

26. Arrhenius plot of the reaction of $\mathrm{OH}$ with methanol. Also shown are previous studies of Hess and Tully ${ }^{14}$ and the recommended Arrhenius prediction of Atkinson. ${ }^{13}$.

27. Arrhenius plot of the reaction of $\mathrm{OH}$ with ethanol. Also shown are previous studies of Hess and Tully 15 and the recommended Armenius prediction of Atkinson. ${ }^{13}$.

28. A reaction pathway diagram for methanol oxidation. . . . . . . . . 32 
29. A reaction pathway diagram for ethanol oxidation.

33 


\section{List of Tables}

Page

1. Initial Experimental Conditions c . . . . . . . . . . . . . 4

2. GC-TCD Conditions. . . . . . . . . . . . . . . . . . 5

3. GC-MS Conditions. . . . . . . . . . . . . . . . . . 5

4. Emissions Comparison of Alcohol Alternative Fuels. . . . . . . . 21

5. Emissions Comparison of Hydrocarbon Alternative Fuels. • . . . . . 22 


\section{Introduction}

The National Renewable Energy Laboratory (NREL) is the field manager for the U.S. Department of Energy (DOE) Alternative Fuels Utilization Program (AFUP). The goal of the AFUP is to develop and advance technology that allows an effective, optimum use of nonpetroleum-based transportation fuels, while complying with modern constraints, such as vehicle emissions. For alternative fuels to be viable candidates to replace petroleum-based counterparts it must be demonstrated that their impact on air quality will be no worse than that of existing fuels and preferably show characteristics that will improve air quality. To make this determination, an extensive program is necessary to identify the atmospheric reactivity of the exhaust species from alternative fuels. For comparison purposes, similar analyses are being performed on advanced petroleum-based fuels.

Because of the nation's continuing concern about air pollution, Congress enacted the Clean Air Act Amendments of 1990. The provisions will force broad changes in fuels and vehicles. For example, reformulated gasolines and alternative fuels are receiving wide attraction as industry struggles to comply with the amendments. At the same time, there are many basic scientific questions about the benefits of switching to alternative fuels. The scientific community does not adequately understand the durability and emission performance of candidate alternative fuels. Additional research is needed, including the ultimate impact on air quality, to identify acceptable alternatives for conventional transportation fuels.

The overall objective of this project is to determine the impact of alternative fuels on air quality, particularly ozone formation. The objective will be met through three steps: 1) qualitative identification of alternative fuel combustion products, 2) quantitative measurement of specific emission levels of these products, and 3) determination of the fate of the combustion products in the atmosphere. The alternative fuels of interest are methanol, ethanol, natural gas; and LP gas.

The role of the University of Dayton Research Institute (UDRD) in this project is two-fold. First, fused silica flow reactor instrumentation is being used to obtain both qualitative identification and quantitative data on the thermal degradation products from the fuel-lean (oxidative), stoichiometric, and fuel-rich (pyrolytic) decomposition of methanol, ethanol, liquefied petroleum gas, and natural gas. Secondly, a laser photolysis/laser-induced fluorescence (LP/LIF) apparatus is being used to determine the rates and mechanisms of reaction of selected degradation products under atmospheric conditions.

This draft final report contains the results of the second year of the study. We initially discuss the results of our flow reactor studies. This is followed by a discussion of our initial results from our LP/LIF studies of the reaction of hydroxyl $(\mathrm{OH})$ radicals with methanol and ethanol. In the coming year, we plan to obtain quantitative data on the oxidation of methyl-t-butylether and reformulated gasoline under fuel-lean, stoichiometric, and fuel-rich conditions. We also plan to conduct a mechanistic analysis of the reaction of $\mathrm{OH}$ with acetaldehyde and formaldehyde over an extended temperature range. 


\section{Task 1 - High Temperature Flow Reactor Studies of the Combustion of Alternative Fuels}

The following sections present the experimental approach, a summary of the results obtained during the past year, and a discussion of the significance of the experimental findings.

\section{Experimental Approach}

During the past year, we have examined the thermal degradation behavior of methanol, ethanol, natural gas, and LP gas using a 1.13-cm i.d. fused silica flow reactor coupled to two different analytical detection systems (see Fig. 1). We have utilized gas chromatography (HP 5890 ) coupled to a modulated thermal conductivity detector (GC-TCD) to obtain quantitative reaction byproduct data for organic compounds ranging from methane to ethyl benzene. A more sensitive gas chromatographic-mass spectrometric detector (HP 5970) (GC-MS) has also been utilized in selected semi-quantitative experiments of each of these four fuels. The experimental approach is discussed in greater detail in the following paragraphs.

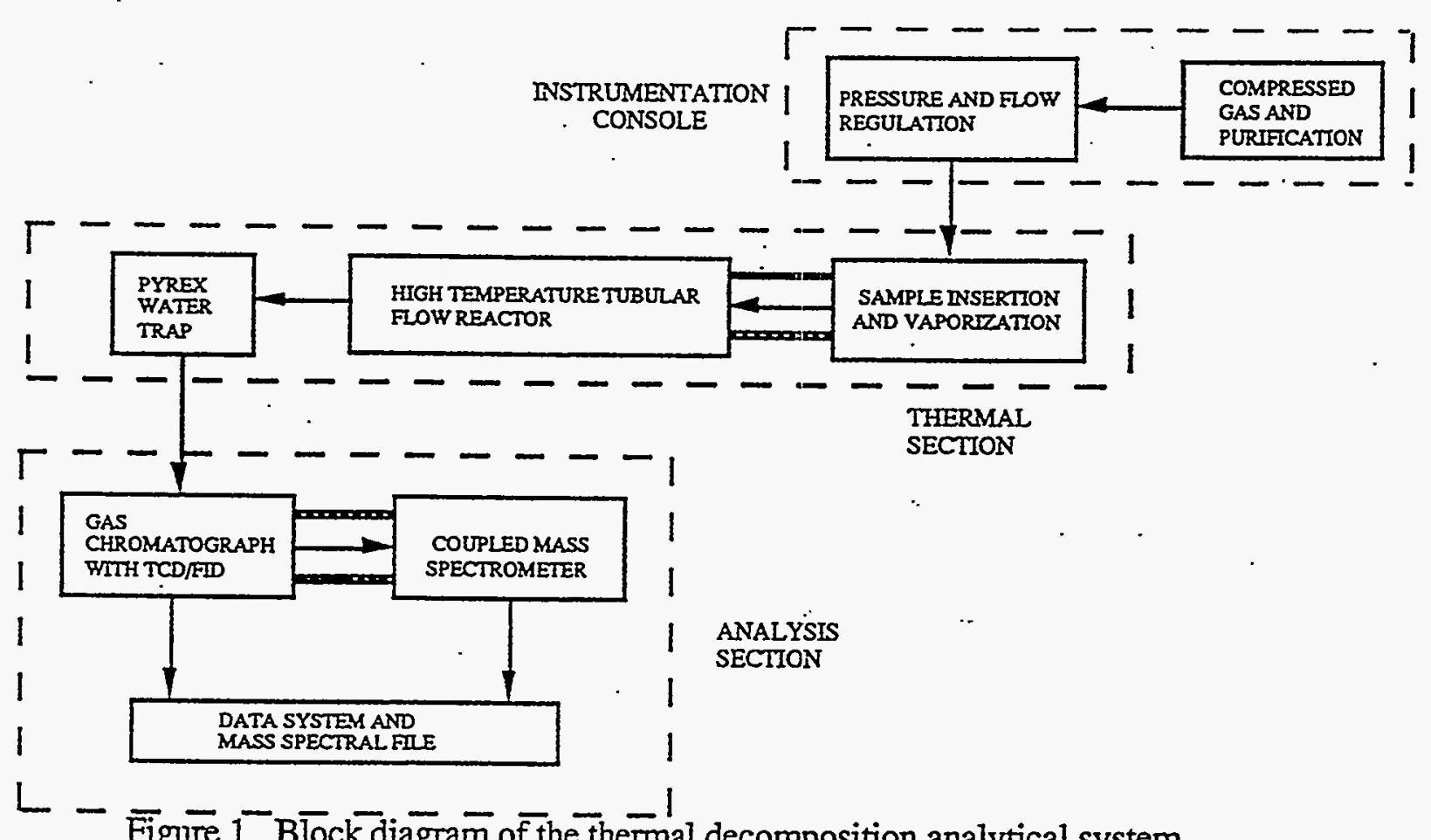

The quantitative experiments were conducted using a $1.13-\mathrm{cm}$ i.d. $\left(69 \mathrm{~cm}^{3}\right.$ volume) helical, tubular flow reactor illustrated in Fig. 2 and housed in a high-temperature three-zone Lindberg furnace (Model 5457). The furnace was designed for continuous operation at temperatures up to $1200^{\circ} \mathrm{C}$, and the three zones were heated independently allowing precise control of the axial reactor temperature profile. This system permitted experiments to be conducted up to $1100^{\circ} \mathrm{C} .1$ 


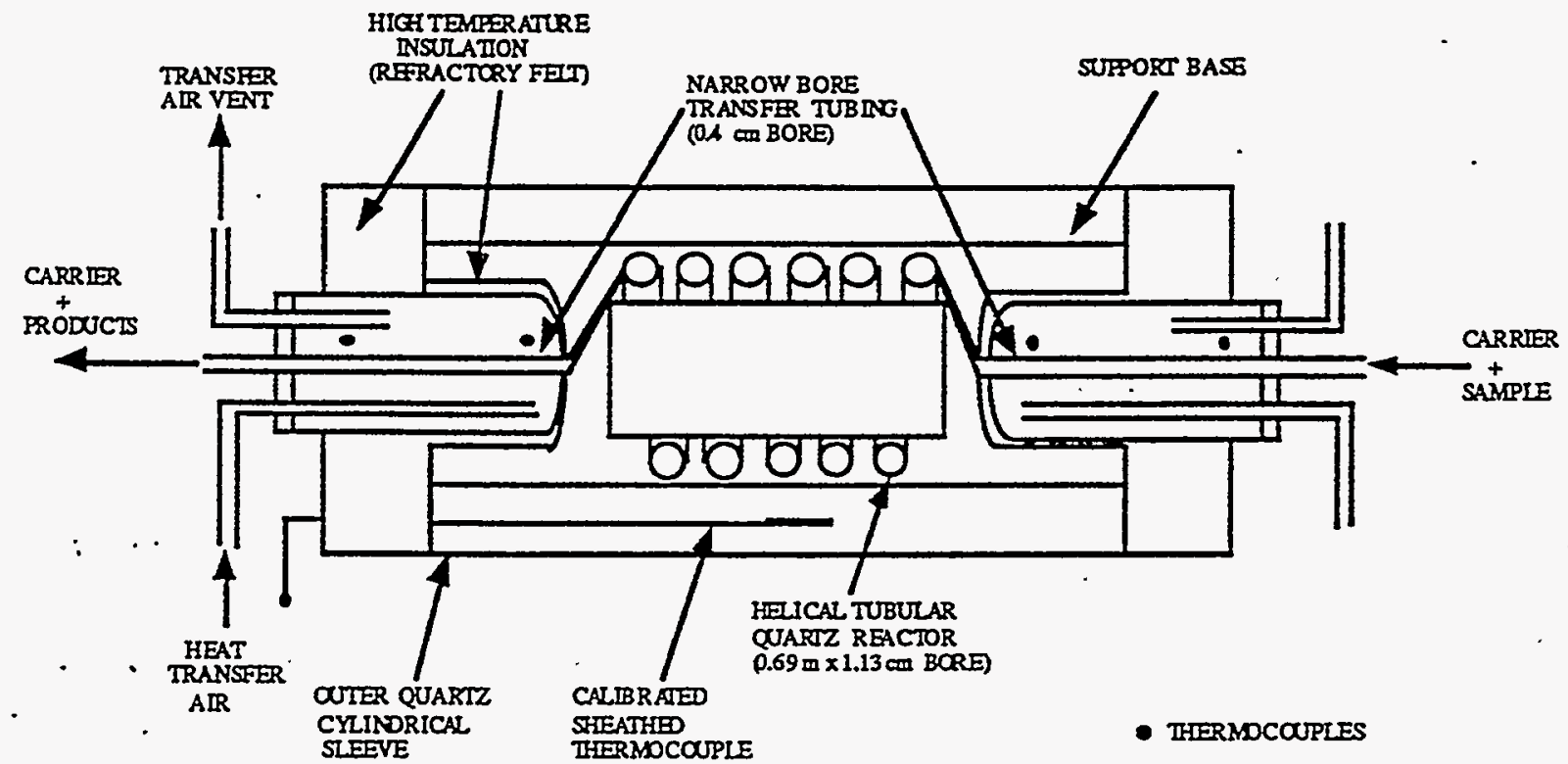

Figure 2. Schematic of the helical, fused silica flow reactor.

Fig. 3 presents the time-temperature profile for gas-phase species examined in these experiments. The square-wave temperature profile is based on unshielded thermocouple wire measurements at various locations within the reactor assembly. The residence times denoted in Fig. 2 are calculated based on volumetric flow measurements and the assumption of a parabolic flow velocity distribution throughout the gas flow-paths. ${ }^{1}$

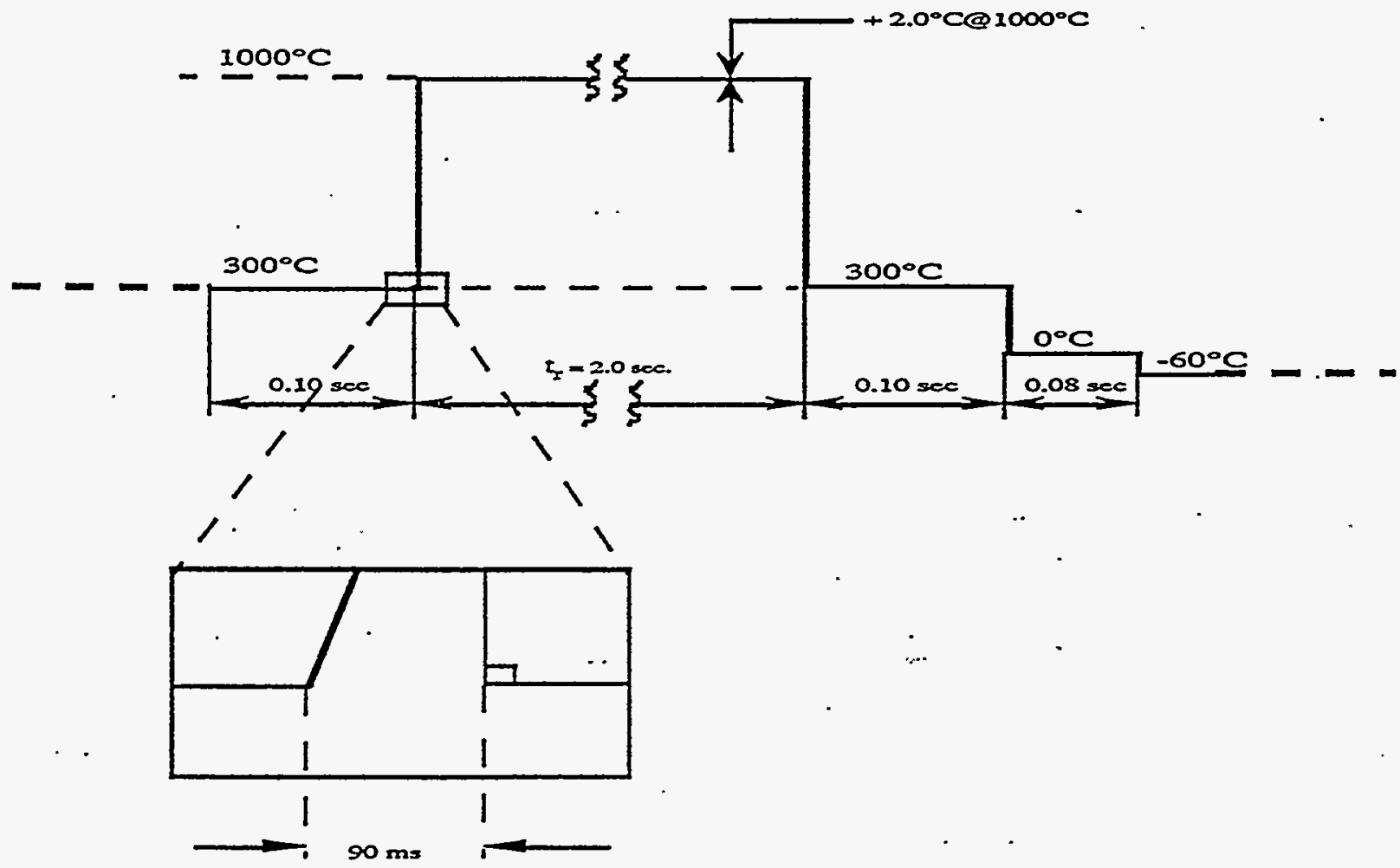

Figure 3. Schematic of time/temperature history of sample injection, high-temperature thermal exposure, and downstream quenching and separation of reaction byproducts. 
Following metered gas-phase sample injection, and high-temperature exposure, the thermal degradation byproducts were swept by helium carrier gas through a ice-cooled, glass frit held at $-0^{\circ} \mathrm{C}$ and then to the head of a GC column held at $-60^{\circ} \mathrm{C}$. The porous frit effectively trapped water vapor and the water-soluble partial oxidation organic byproducts during the data acquisition portion of the experiments. During the analytical portion of the experiment, the frit was allowed to warm to ambient temperatures and the organic byproducts (and a fraction of the water) were then purged from the frit using high purity helium carrier gas. The reduced quantities of water present in the GC column permitted baseline GC separation and quantification of the organic intermediates. A trial and error procedure resulted in the optimum He carrier gas velocity for quantitative purging of organic bypraducts from the frit to the GC column.

Methanol and ethanol samples (Aldrich) were used as received. GC-MS analysis of the both samples indicated $99.9+\%$ purity. The natural gas used for these experiments was obtained locally and consisted of the following components ( $\mathrm{v} / \mathrm{v}$ as determined by GC-TCD analysis): methane $(87.4 \%)$, ethane, $(6.5 \%)$, propane $(3.1 \%)$, n-butane $(1.8 \%)$, and n-pentane and larger alkanes (1.2\%). The LP gas mixture was prepared in our laboratory and was of the same composition as used by Southwest Research Institute in their experiments, ${ }^{2}$ i.e., propane (91.4\%), propene $(6.1 \%)$, ethane $(2.0 \%)$, methane $(0.1 \%)$, and n-butane and larger hydrocarbons $(0.4 \%)$.

Table 1 summarizes the initial experimental conditions. Experiments were conducted for four different fuel/oxygen equivalence ratios $(\Phi)$ ranging from fuel-lean to stoichiometric to fuelrich to oxygen-free pyrolysis (fuel/oxygen equivalence ratio is defined as the actual fuel/oxygen molar ratio divided by the stoichiometric fuel/oxygen molar ratio). The fuel/oxygen equivalence ratio was controlled by a priori mixing of liquid fuel aliquots with oxygen (diluted in helium) in previously cleaned and dried glass sample vessels of known volume. Data were obtained for isothermal reactor exposures ranging from 300 to $1050^{\circ} \mathrm{C}$. The absolute pressure for all experiments was $1.42 \mathrm{~atm}$.

Table 1. Initial Experimental Conditions

\begin{tabular}{||l|c|c|c|}
\hline \multirow{2}{*}{ Fuel } & $\Phi$ & $\begin{array}{c}\text { Initial } \\
\text { Concentration, } \\
\text { ppm (v/v) }\end{array}$ & $\mathrm{t}_{\mathrm{r}}(\mathrm{sec})$ \\
\hline Methanol & 0.7 & 910 & 2.0 \\
\hline & 1.0 & 1230 & $1.0,2.0$ \\
\hline & 1.5 & 1920 & 2.0 \\
\hline Ethanol & Pyrolysis & 1760 & $1.0,2.0$ \\
\hline & 0.7 & 460 & 2.0 \\
\hline & 1.0 & 640 & $1.0,2.0$ \\
\hline & 1.5 & 1040 & 2.0 \\
\hline Natural Gas & Pyrolysis & 980 & $1.0,2.0$ \\
\hline & 0.7 & 660 & 2.0 \\
\hline & 1.0 & 780 & $1.0,2.0$ \\
\hline & 1.7 & 930 & 2.0 \\
\hline LP Gas & Pyrolysis & 1280 & $1.0,2.0$ \\
\hline & 0.7 & 720 & 2.0 \\
\hline & 1.0 & 890 & $1.0,2.0$ \\
\hline & 1.7 & 980 & 2.0 \\
\hline & Pyrolysis & 1290 & $1.0,2.0$ \\
\hline
\end{tabular}


Capillary column gas chromatography was utilized for product separation. Product detection was accomplished using a modulated thermal conductivity detector. A porous layer open tubular column was used for analysis of light hydrocarbons and oxygenates. The higher temperature capability $\left(260^{\circ} \mathrm{C}\right.$ ) of a $25-\mathrm{m}, 0.25-\mathrm{mm}$ i.d., DB-1 capillary column was utilized for several experiments to determine yields of higher molecular weight organic byproducts. Analytical standards were used to provide positive identification of thermal reaction products. Quantification was obtained from least squares analysis of four point calibration curves. Table 2 summarizes the GC-TCD conditions.

Table 2. GC-TCD Conditions

\begin{tabular}{|c|c|}
\hline GC Columns: & GS-Q, 30 $\mathrm{m} \times 0.53 \mathrm{~mm}$ i.d. \\
& PLOT column \\
& DB- $1,25 \mathrm{~m} \times 0.25 \mathrm{~mm}$ i.d. \\
& $0.25 \mu \mathrm{m}$ film thickness \\
\hline GC Temperature Program: & $-60^{\circ} \mathrm{C}$ to $230^{\circ} \mathrm{C} @ 15^{\circ} \mathrm{C}$ min (GS-Q) \\
& $-60^{\circ} \mathrm{C}$ to $260^{\circ} \mathrm{C} @ 15^{\circ} \mathrm{C}$ min (DB-1) \\
\hline Detector Temperature: & $240^{\circ} \mathrm{C}$ \\
\hline Carrier Gas: & Helium \\
\hline Run Time: & $24.33 \mathrm{~min}$ (GS-Q), 26.33 min (DB-1) \\
\hline
\end{tabular}

Following the quantitative experiments, several semi-quantitative experiments were conducted using the same experimental apparatus coupled to a more sensitive GC-MS analytical system. These experiments examined the thermal degradation behavior of each fuel for the same initial conditions as the GC-TCD experiments, with a particular emphasis on detection of trace byproducts. Table 3 summarized the GC-MS conditions for these experiments.

Table 3. GC-MS Conditions

\begin{tabular}{|c|c|}
\hline \hline GC Columns: & GS-Q, 30 m $0.53 \mathrm{~mm}$ i.d. \\
& PLOT column \\
& DB-1,25 m x 0.25 mm i.d., \\
& $0.25 \mu \mathrm{m}$ film thickness \\
\hline GC Temperature Program: & $-60^{\circ} \mathrm{C}$ to $230^{\circ} \mathrm{C} @ 15^{\circ} \mathrm{C} / \mathrm{min}$ (GS-Q) \\
& $-60^{\circ} \mathrm{C}$ to $260^{\circ} \mathrm{C} @ 15^{\circ} \mathrm{C} / \mathrm{min}$ (DB-1) \\
\hline GC-MS Transfer Line Temperature: & $275^{\circ} \mathrm{C}$ \\
\hline Carrier Gas:, & Helium \\
\hline Ionization Mode & Electron Impact \\
\hline Electron Energy: & $70 \mathrm{eV}$ \\
\hline Electron Mültiplier Setting: & 2600 units \\
\hline Mass range Scanned: & $12-350$ amu \\
\hline Scan Speed: & 1 sec/decade \\
\hline Run Time: & 24.33 min (GS-Q), 26.33 min (DB-1) \\
\hline
\end{tabular}

\section{Results}

We first present the results for the two alcohol fuels, methanol and ethanol. This is followed by a presentation of the results for the two hydrocarbon-based fuels, natural gas and LP gas. 


\section{Methanol}

Fig. 4 presents a representative thermal decomposition profile for methanol. This particular profile was obtained under stoichiometric conditions for a gas-phase residence time of $2.0 \mathrm{sec}$. Methanol oxidation initiates at temperatures of $-450^{\circ} \mathrm{C}$. Conversion was observed to be relatively slow up to temperatures of $700^{\circ} \mathrm{C}$. Over this temperature regime, formaldehyde was observed as the primary organic reaction byproduct with trace $(<0.5 \%)$ yields of ethene and ethane also observed. Above $700^{\circ} \mathrm{C}$, methanol conversion is very rapid to the extent that methanol was not observed above a detection limit of $0.05 \%$ at $725^{\circ} \mathrm{C}$. Formaldehyde, ethene, and ethane were also observed to be completely destroyed at a temperature of $750^{\circ} \mathrm{C}$.

Methanol oxidation was not a strong function of equivalence ratio. The same reaction byproducts were observed under fuel-lean $(\Phi=0.7)$ and fuel-rich $(\Phi=1.5)$ conditions, with maximum yields varying by less than a factor of 3 .

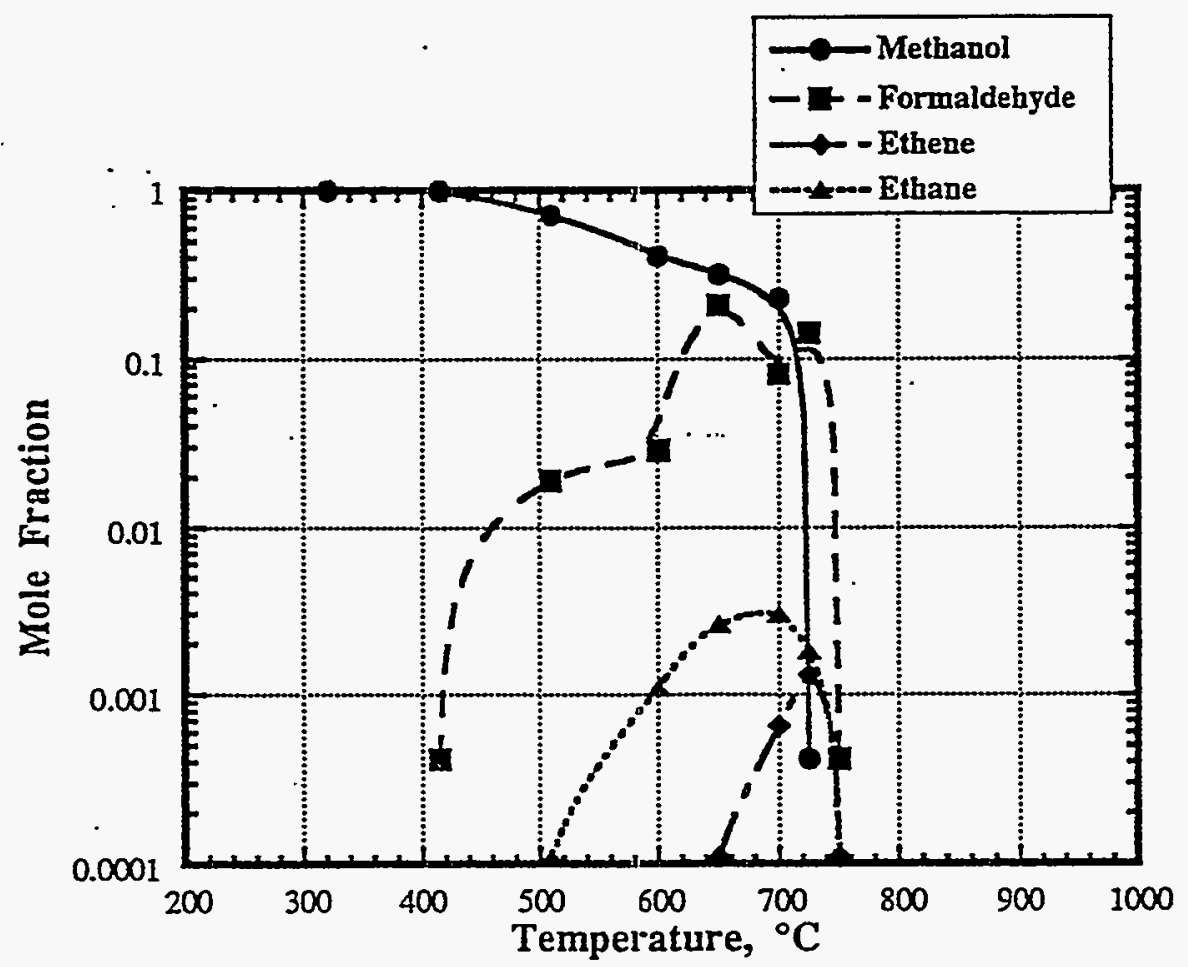

Figure 4. Organic byproduct distributions from the thermal degradation of methanol. $\phi=1.0$. $\mathrm{t}_{\mathrm{r}}=2.0 \mathrm{~s} .\left[\mathrm{CH}_{3} \mathrm{OH}\right]_{0}=1230 \mathrm{ppm}$.

Figure 5 presents two semi-quantitative total ion chromatograms (GC-MS detection) obtained from the stoichiometric oxidation $\left(800^{\circ} \mathrm{C}\right.$, Fig. $\left.5 \mathrm{a}\right)$ and pyrolysis $\left(1050^{\circ} \mathrm{C}\right.$, Fig. $\left.5 \mathrm{~b}\right)$ of methanol for residence times of $1.0 \pm 0.1 \mathrm{sec}$. No.organic byproducts were observed under stoichiometric conditions. Methane, ethene and acetylene were observed as the only organic byproducts under pyrolytic conditions. Unlike hydrocarbon-based fuels, methanol pyrolysis did not exhibit any evidence of hydrocarbon molecular growth based the lack of detection of aromatic and polycyclic aromatic hydrocarbons.

The experimental results are generally consistent with our earlier studies of methanol oxidation using a smaller diameter flow reactor. 3,4 Byproducts observed in both studies were methane, ethane, ethene, and formaldehyde. Acetone and trioxane were observed as minor 
byproducts in our earlier studies. We attribute their lack of formation in our quantitative studies to the minimized contribution of surface effects both in the high-temperature reactor and in the downstream transfer lines. Their apparent surface-induced formation leads one to consider the effects of surfaces on the formation of pollutants in internal combustion engines.
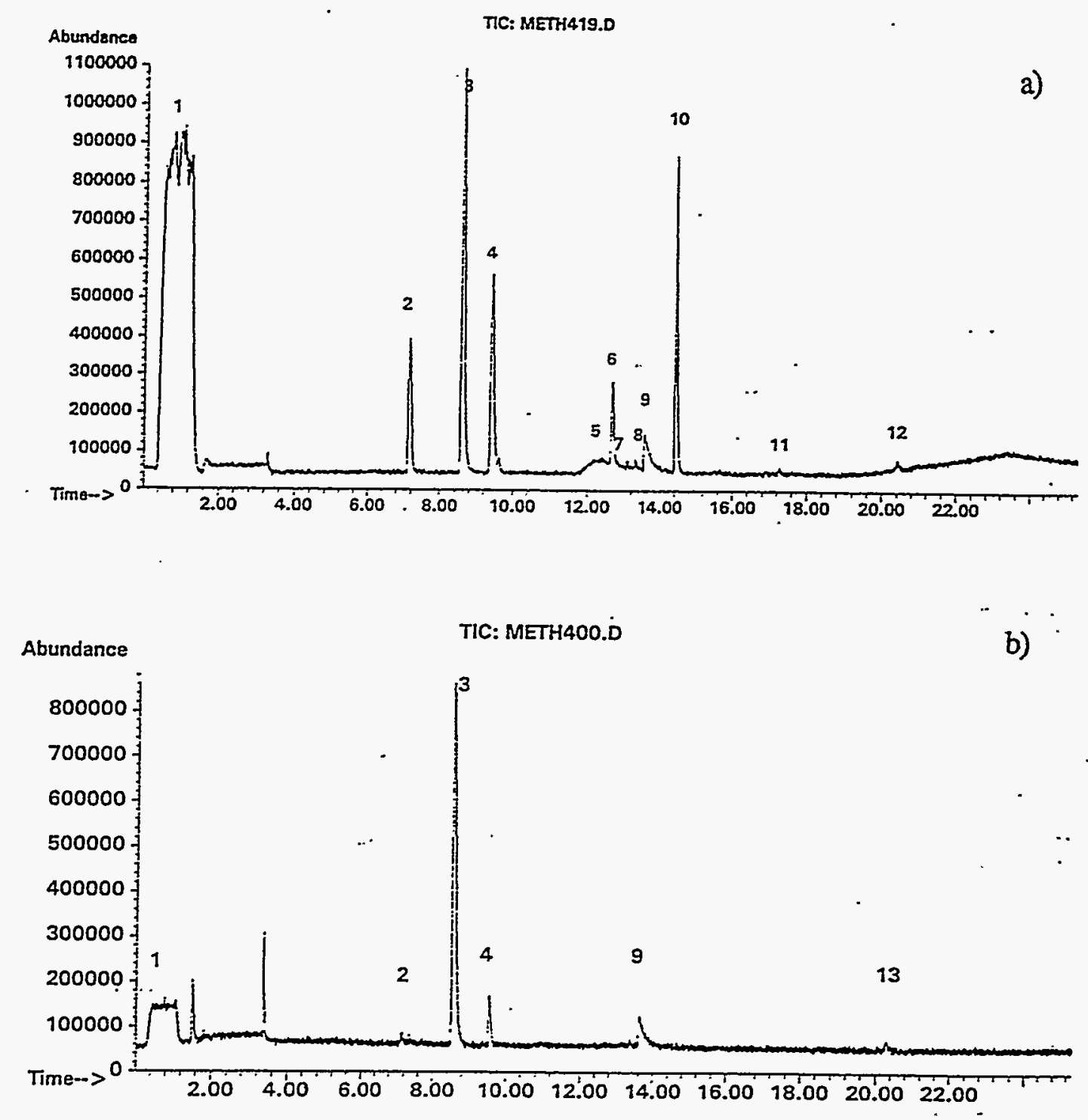
1. $\mathrm{CO}$
6. Propene
11. Acetone
2. $\mathrm{CO}_{2}$
7. 1-Propyne
12. Acetic acid
3. Ethylene
8. 1,2-Propadiene
13. Benzene
4. Acetylene
9. Water
5. $\mathrm{HCHO}$
10. Acetaldehyde

Figure 5. Total ion chromatogram of the thermal degradation of methanol. a) $\phi=1.0, T_{\mathrm{r}}=800^{\circ} \mathrm{C}$, $\mathrm{t}_{\mathrm{r}}=1.1 \mathrm{sec} .\left[\mathrm{CH}_{3} \mathrm{OH}\right]_{0}=1230 \mathrm{ppm}$. b) Pyrolysis, $\mathrm{T}_{\mathrm{r}}=1050^{\circ} \mathrm{C}, \mathrm{t}_{\mathrm{r}}=0.9 \mathrm{sec},\left[\mathrm{CH}_{3} \mathrm{OH}\right]_{0}=1760$ ppm. 


\section{Ethanol}

Fig. 6 presents a representative thermal decomposition profile for ethanol. This particular profile was obtained under stoichiometric conditions for a gas-phase residence time of $2.0 \mathrm{sec}$. Ethanol oxidation initiates at temperatures of $350^{\circ} \mathrm{C}$. Conversion was relatively slow up to temperatures of $650^{\circ} \mathrm{C}$. Over this temperature regime, acetaldehyde was the primary organic reaction byproduct. Above $650^{\circ} \mathrm{C}$, ethanol conversion is very rapid to the extent that ethanol was not observed above a detection limit of $0.05 \%$ at $700^{\circ} \mathrm{C}$. For this temperature regime of greater ethanol conversion, several organic byproducts were observed including methane, ethane, ethene, and propene. Acetic acid was also observed in trace yields between temperatures of 600 and $800^{\circ} \mathrm{C}$. The $C_{1}$ and $C_{2}$ hydrocarbon byproducts exhibited maximum yields of $\sim 10 \%$; maximum yields of propene were $\sim 1 \%$. In contrast to methanol, the observed organic byproducts were significantly more stable than the parent fuel. Ethene and ethane were the most stable organic byproducts, requiring temperatures of $900^{\circ} \mathrm{C}$ for their complete destruction.

Like methanol, ethanol oxidation was not observed to be a strong function of reaction stoichiometry. The same reaction byproducts were observed under fuel-lean $(\Phi=0: 7)$ and fuelrich $(\Phi=1.5)$ conditions, with maximum yields varying by less than a factor of 2 .

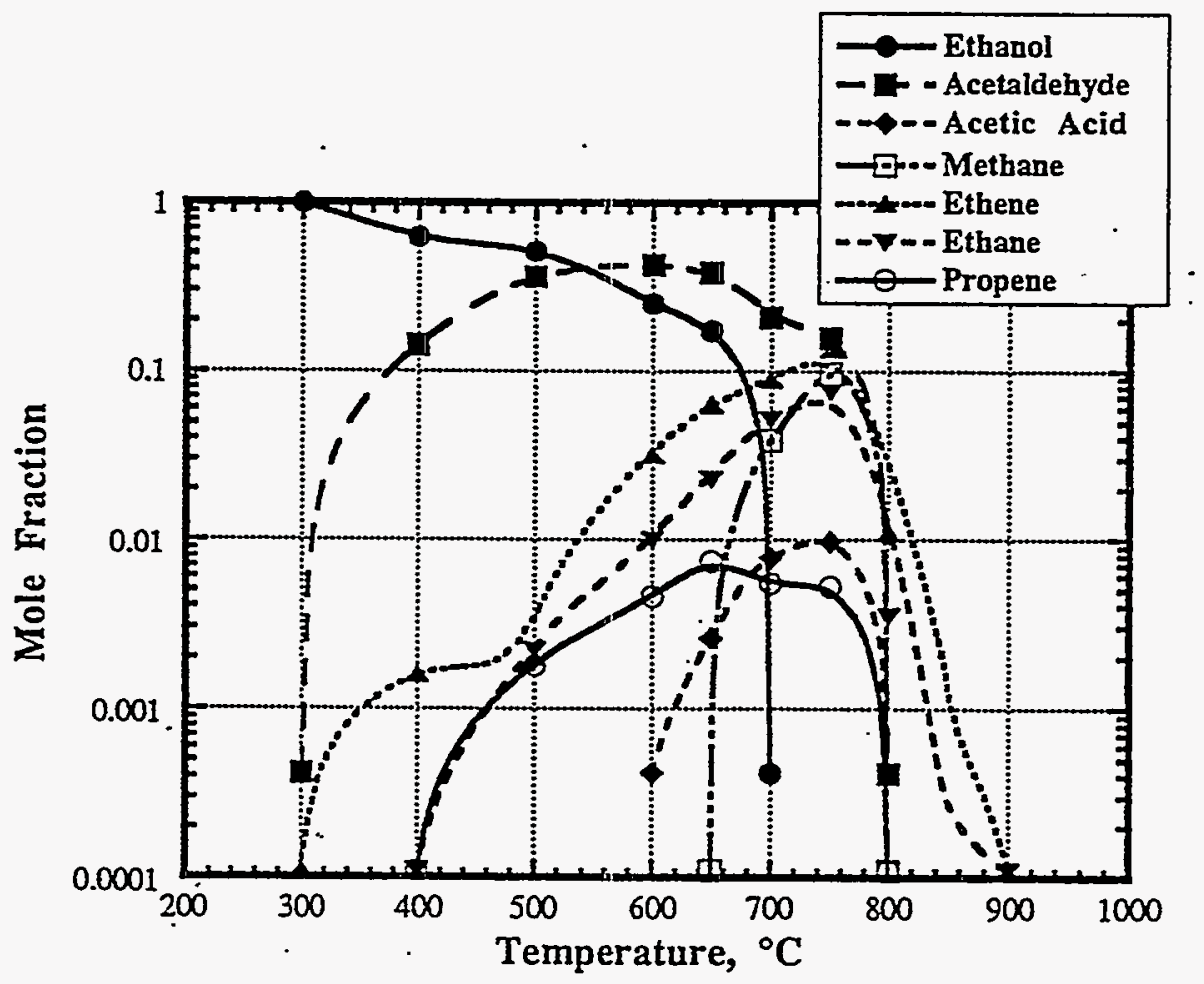

Figure 6. Organic byproduct distributions from the thermal degradation of ethanol. $\phi=1.0 . t_{r}=$ 2.0 s. $\left[\mathrm{CH}_{3} \mathrm{CH}_{2} \mathrm{OH}\right]_{0}=640 \mathrm{ppm}$.

Figure 7 presents two semi-quantitative total ion chromatograms obtained from the stoichiometric oxidation $\left(800^{\circ} \mathrm{C}\right.$, Fig. 7a) and pyrolysis $\left(1050^{\circ} \mathrm{C}\right.$, Fig. 7b) of ethanol for residence times of $1.0 \pm 0.1 \mathrm{sec}$. Under both conditions, ethene, acetylene, and benzene were observed as organic byproducts. The enhanced sensitivity of the mass spectrometer is clearly shown in the stoichiometric experiment, where traces of 1-propyne, 1,2-propadiene, acetone, and acetic acid were observed. The trace levels of $\mathrm{C}_{3}$ intermediates and benzene provide evidence of hydrocarbon 
molecular growth and the potential formation of substituted aromatic and polycyclic aromatic hydrocarbons from ethanol thermal degradation. These results also indicate that, due to the incorporation of oxygen in the fuel, hydrocarbon molecular growth is not necessarily promoted under pyrolytic conditions.
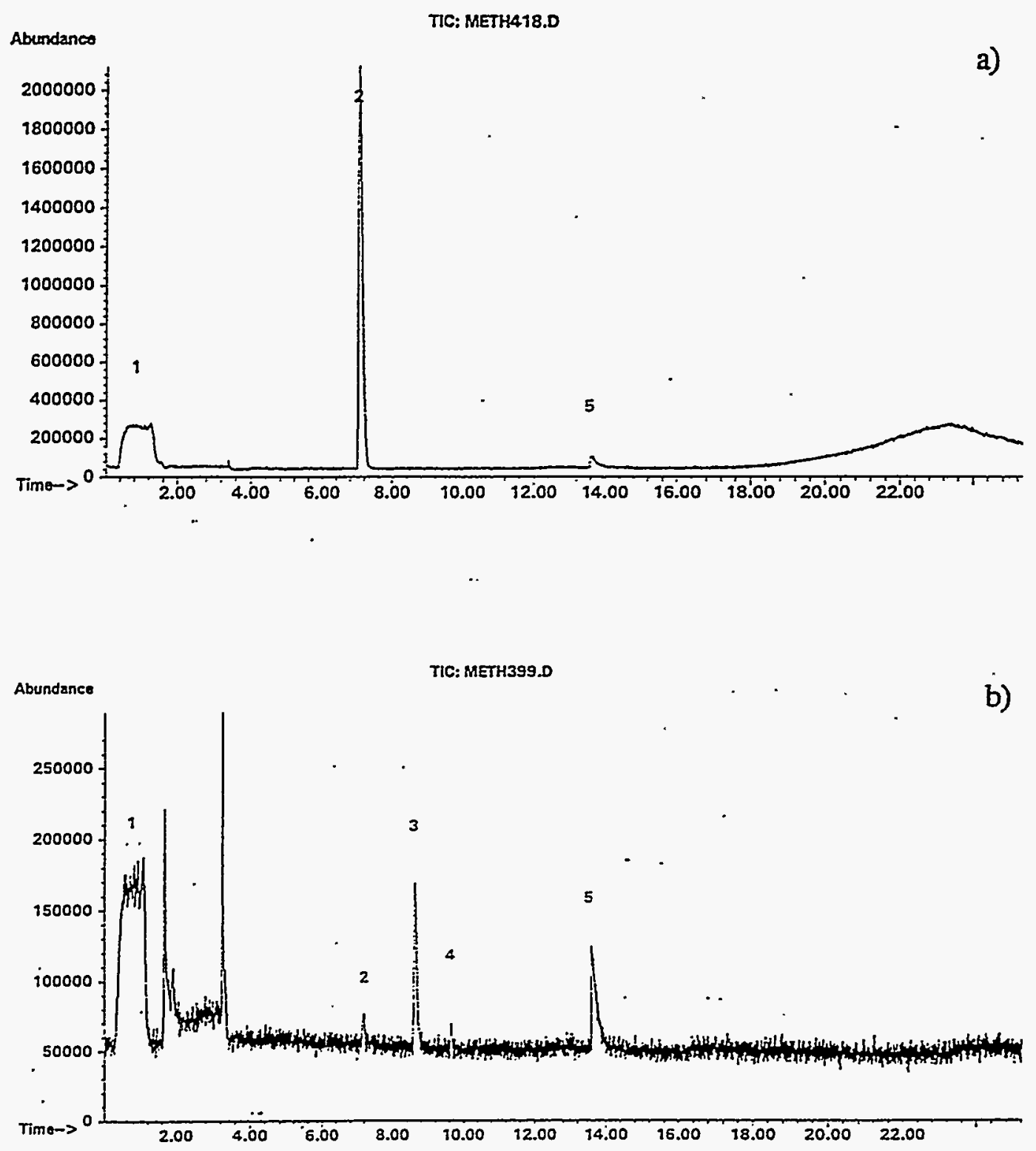
1. $\mathrm{CO}$
4. Acetylene
2. $\mathrm{CO}_{2}$
5. Water
3. Ethylene

Figure 7. Total ion chromatogram of the thermal degradation of ethanol. a) $\phi=1.0, T_{r}=800^{\circ} \mathrm{C}, t_{r}$ $=1.1$ sec. $\left[\mathrm{CH}_{3} \mathrm{CH}_{2} \mathrm{OH}\right]_{0}=640$ ppm. b) Pyrolysis, $\mathrm{T}_{\mathrm{r}}=1050^{\circ} \mathrm{C}, \mathrm{t}_{\mathrm{r}}=0.9 \mathrm{sec},\left[\mathrm{CH}_{3} \mathrm{CH}_{2} \mathrm{OH}\right]_{0}=$ 980 ppm. 
The experimental results are generally consistent with our earlier studies of ethanol oxidation using a smaller diameter flow reactor. 3,4 Byproducts observed in both studies were methane, ethane, ethene, acetylene, propene, formaldehyde, acetaldehyde, acetone, and acetic acid. Ethyl acetate, 3-hydroxyl-2-butanone, and 2,3-butanediol were observed as trace byproducts in our earlier studies. We attribute their lack of formation in our quantitative studies to the minimized contribution of surface effects both in the high-temperature reactor and in the downstream transfer lines.

\section{Natural Gas}

Fig. 8 presents a representative thermal decomposition profile for natural gas (predominantly methane). This particular profile was obtained under stoichiometric conditions for a gas-phase residence time of $2.0 \mathrm{sec}$. Methane was observed to be much more stable than either methanol or ethanol. Complete chromatographic separation of methane from oxygen was not achievable until temperatures of $750^{\circ} \mathrm{C}$. Measurements at $750^{\circ} \mathrm{C}, 800^{\circ} \mathrm{C}$, and $850^{\circ} \mathrm{C}$, and knowledge of the initial composition of the natural gas indicated that relatively slow oxidation of methane occurs between temperatures of 300 and $850^{\circ} \mathrm{C}$. Organic byproducts (even after accounting for the initial mole fractions of ethene and ethane) were not observed suggesting that carbon monoxide and carbon dioxide were the primary reaction products. Above $850^{\circ} \mathrm{C}$, methane oxidation was rapid with conversion to analytical detection limits at $1000^{\circ} \mathrm{C}$. At these elevated temperatures, ethene and propene were the only organic reaction byproducts observed with maximum yields of $\sim 10 \%$ and $\sim 1 \%$, respectively. These organic byproducts were completely destroyed at temperatures of $1050^{\circ} \mathrm{C}$ and $1000^{\circ} \mathrm{C}$, respectively. The minor constituents of natural gas, ethane and propane were completely destroyed by temperatures of $1000^{\circ} \mathrm{C}$ and $850^{\circ} \mathrm{C}$, respectively.

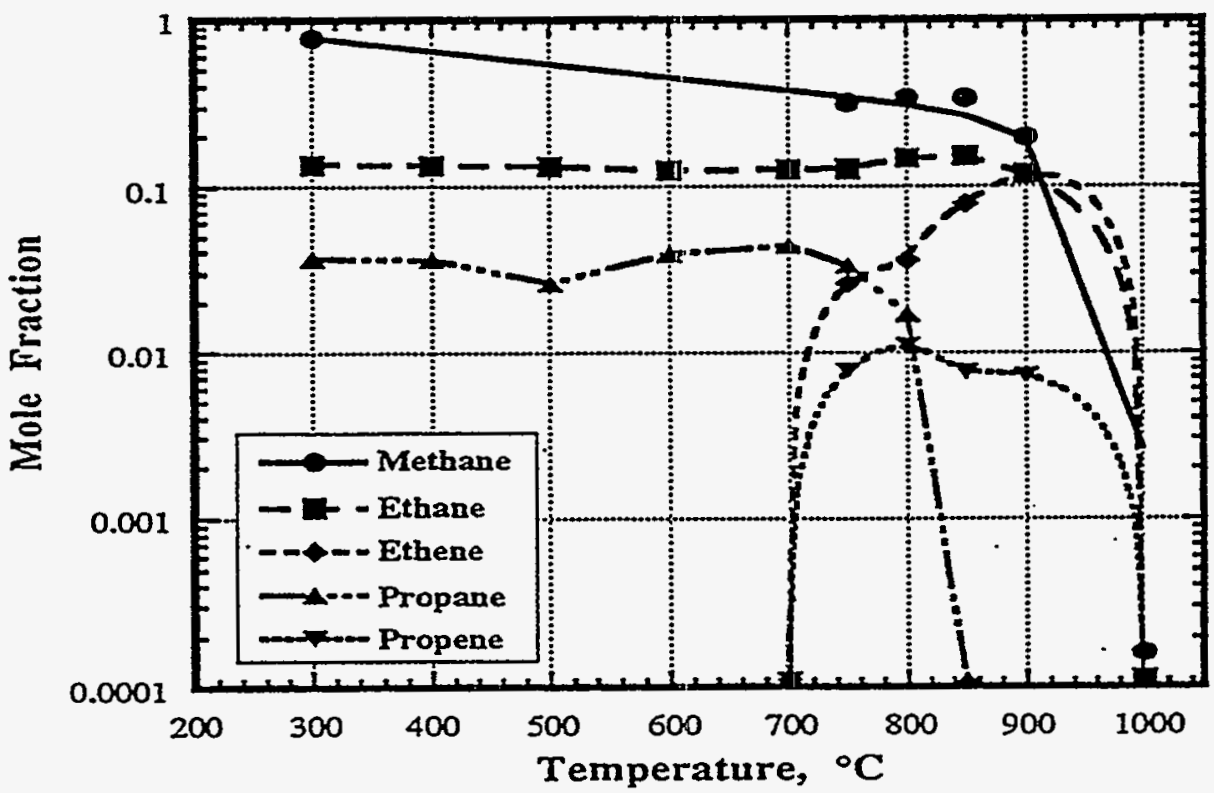

Figure 8. Organic byproduct distributions from the thermal degradation of natural gas. $\phi=1.0 . \mathrm{t}_{\mathrm{r}}=2.0 \mathrm{~s}$. $\left[\mathrm{CH}_{4}\right]_{0}=680 \mathrm{ppm} .\left[\mathrm{C}_{2} \mathrm{H}_{6}\right]_{0}=50 \mathrm{ppm} .\left[\mathrm{C}_{3} \mathrm{H}_{8}\right]_{0}=25 \mathrm{ppm}$. The initial concentrations of butane, pentane, and hexane were less than $15 \mathrm{ppm}$.

Natural gas oxidation was observed to be a strong function of reaction stoichiometry. Although the same reaction byproducts were observed under fuel-lean $(\Phi=0.7)$ and fuel-rich $(\Phi=$ $1.5)$ conditions, hydrocarbons exhibited greater stability at elevated temperatures under fuel-rich conditions. No oxygenated intermediates were observed under either fuel-lean or fuel-rich 
experimental conditions. Figs. 9 and 10 present representative thermal decomposition profiles for natural gas under fully pyrolytic (oxygen-free) conditions for a gas-phase residence time of 2.0 sec. Under these conditions, the rapid destruction (oxidation) of methane at temperatures between 850 and $1050^{\circ} \mathrm{C}$ was not observed At these temperatures, pronounced hydrocarbon molecular growth was observed. Observed organic byproducts which formed above $700^{\circ} \mathrm{C}$ were ethene and propene. At temperatures above $850^{\circ} \mathrm{C}$, the observed byproducts included ethane, n-butane, benzene, and ethyl benzene. These latter byproducts continued to form at temperatures of $1050^{\circ} \mathrm{C}$ while yields of ethene and propene were below analytical detection limits.

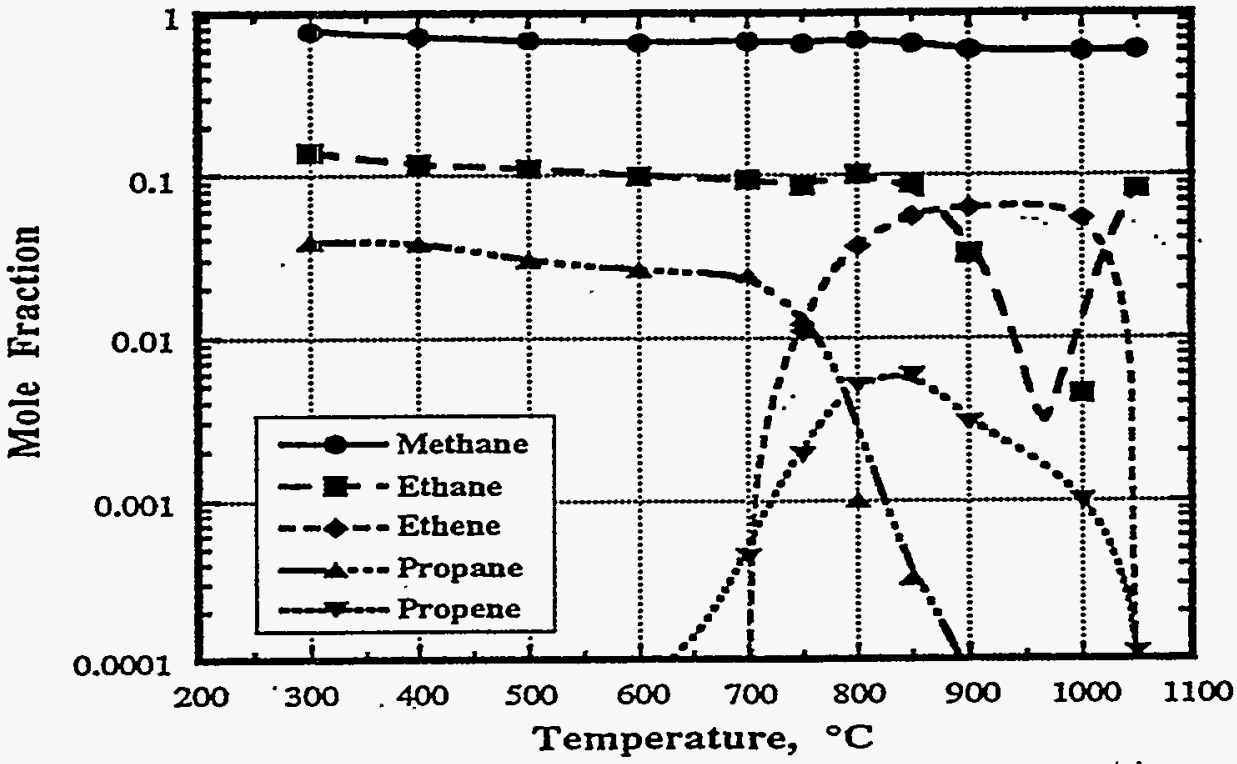

Figure 9. Organic byproduct distributions $\left(\leq \mathrm{C}_{3}\right)$ from the pyrolytic thermal degradation of natural gas. $\mathrm{t}_{\mathrm{r}}=2.0 \mathrm{~s}$. $\left[\mathrm{CH}_{4}\right]_{0}=1120 \mathrm{ppm}$. $\left[\mathrm{C}_{2} \mathrm{H}_{6}\right]_{0}=85 \mathrm{ppm} .\left[\mathrm{C}_{3} \mathrm{H}_{8}\right]_{0}=40 \mathrm{ppm}$. The initial concentrations of butane, pentane, and hexane were less than $25 \mathrm{ppm}$.

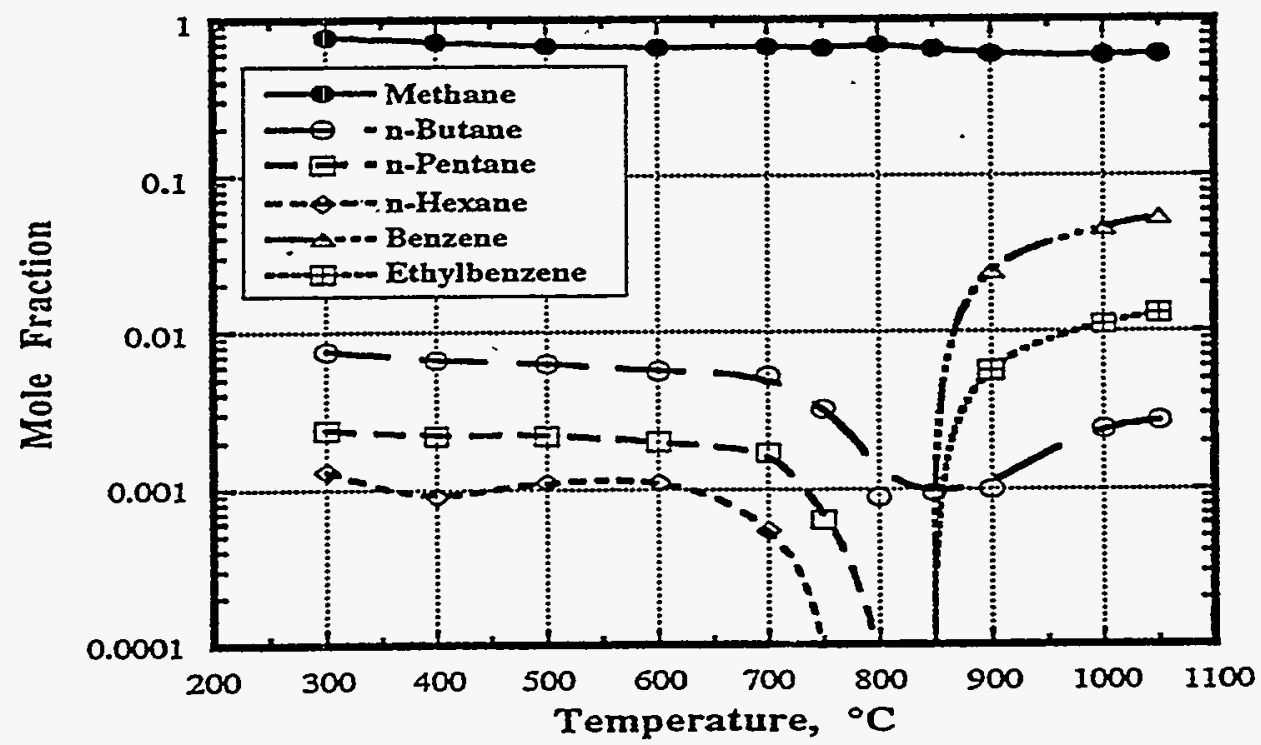

Figure 10. Organic byproduct distributions $\left(>\mathrm{C}_{3}\right)$ from the pyrolytic thermal degradation of natural gas. $\mathrm{t}_{\mathrm{r}}=2.0 \mathrm{~s}$. $\left[\mathrm{CH}_{4}\right]_{0}=1120 \mathrm{ppm} .\left[\mathrm{C}_{2} \mathrm{H}_{6}\right]_{0}=85 \mathrm{ppm} .\left[\mathrm{C}_{3} \mathrm{H}_{8}\right]_{0}=40 \mathrm{ppm}$. The initial concentrations of butane, pentane, and hexane were less than $25 \mathrm{ppm}$. 
Figure 11 presents two semi-quantitative total ion chromatograms obtained from the stoichiometric oxidation $\left(800^{\circ} \mathrm{C}\right.$, Fig. 11a) and pyrolysis $\left(1050^{\circ} \mathrm{C}\right.$, Fig. $\left.11 \mathrm{~b}\right)$ of natural gas for residence times of $1.0 \pm 0.1 \mathrm{sec}$. Under stoichiometric conditions, the increased sensitivity of GCMS detection indicates the presence of $C_{3}$ and $C_{4}$ intermediates including 1,3-butadiene, in addition to the $C_{2}$ intermediates observed from the quantitative analysis for longer residence times. These chromatograms provide a more detailed picture of the pronounced hydrocarbon molecular growth that can occur when the oxygen-free pyrolysis of natural gas occurs.
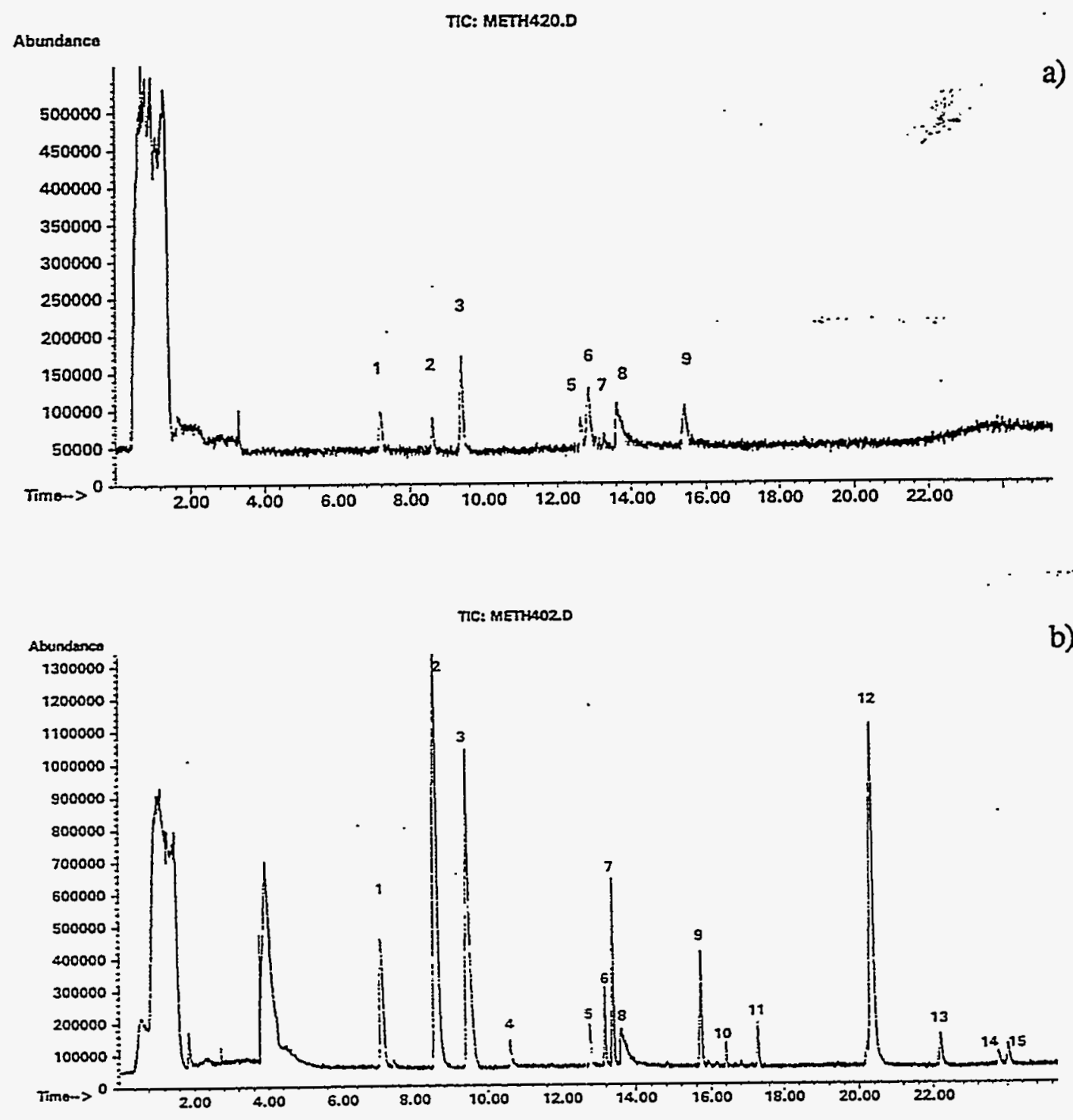
1. $\mathrm{CO}_{2}$
6. Propyne
11. $\mathrm{CS}_{2}$
2. Ethylene
7. 1-2 Propadiene
12. Benzene
3. Acetylene
8. Water
13. Toluene
4. $\mathrm{SO}_{2}$
9. 1-3 Butadiene
14. Phenylethyne
5. Propene
10. 1-3 Butadiyne
15. Styrene

Figure 11. Total ion chromatogram of the thermal degradation of natural gas. a) $\phi=1.0, T_{\mathrm{r}}=$ $800^{\circ} \mathrm{C}, \mathrm{t}_{\mathrm{r}}=1.1 \mathrm{sec}$. b) Pyrolysis, $\mathrm{T}_{\mathrm{r}}=1050^{\circ} \mathrm{C}, \mathrm{t}_{\mathrm{r}}=0.9 \mathrm{sec}$. See Table 3 for initial concentrations. 


\section{LP Gas}

Fig. 12 presents a representative thermal decomposition profile for LP gas (predominantly propane). This particular profile was obtained under stoichiometric conditions for a gas-phase residence time of $2.0 \mathrm{sec}$. Propane was observed to be of intermediate stability between methane (high stability) and both alcohol fuels (low stability). In contrast to methanol, ethanol, and methane, propane did not exhibit two separate temperature regimes of relatively slow and much more rapid reactivity. Reaction initiated at a temperature of $600^{\circ} \mathrm{C}$ and resulted in the formation of ethene as the primary reaction byproduct. Complete destruction was achieved at a temperature of $900^{\circ} \mathrm{C}$. Ethene was the only observed reaction byproduct, with the possible exception of n-butane which may have formed in small yields above its initial concentration in the unreacted mixture. Ethene and the minor constituents of LP gas, ethane, propene, methane, and $n$-butane were completely destroyed at temperatures of $900^{\circ} \mathrm{C}$.

Like natural gas, LP gas oxidation was also observed to be a strong function of reaction stoichiometry. Although the same reaction byproducts were observed under fuel-lean $(\Phi=0.7)$ and fuel-rich $(\Phi=1.5)$ conditions, hydrocarbons exhibited greater stability at elevated temperatures under fuel-rich conditions. Figs. 13 and 14 present representative thermal decomposition profiles for LP gas under fully pyrolytic (oxygen-free) conditions for a gas-phase residence time of 2.0 sec. Under these conditions, propane exhibited two separate temperature regimes of slow and much more rapid reactivity. Reaction initiated at a temperature of $\sim 400^{\circ} \mathrm{C}$ and resulted in the formation of methane, ethane, ethene, propene and 1-butene as reaction byproducts. At temperatures of $800^{\circ} \mathrm{C}$ and above, rapid conversion was observed with complete destruction achieved at a temperature of $900^{\circ} \mathrm{C}$. At these elevated temperatures, pronounced hydrocarbon molecular growth was observed. Observed organic byproducts which formed above $700^{\circ} \mathrm{C}$ included n-pentane, benzene, and ethyl benzene. Propene and 1-butene were completely destroyed at $1000^{\circ} \mathrm{C}$. However, the remaining byproducts still exhibited significant concentrations $(>0.5 \%)$.

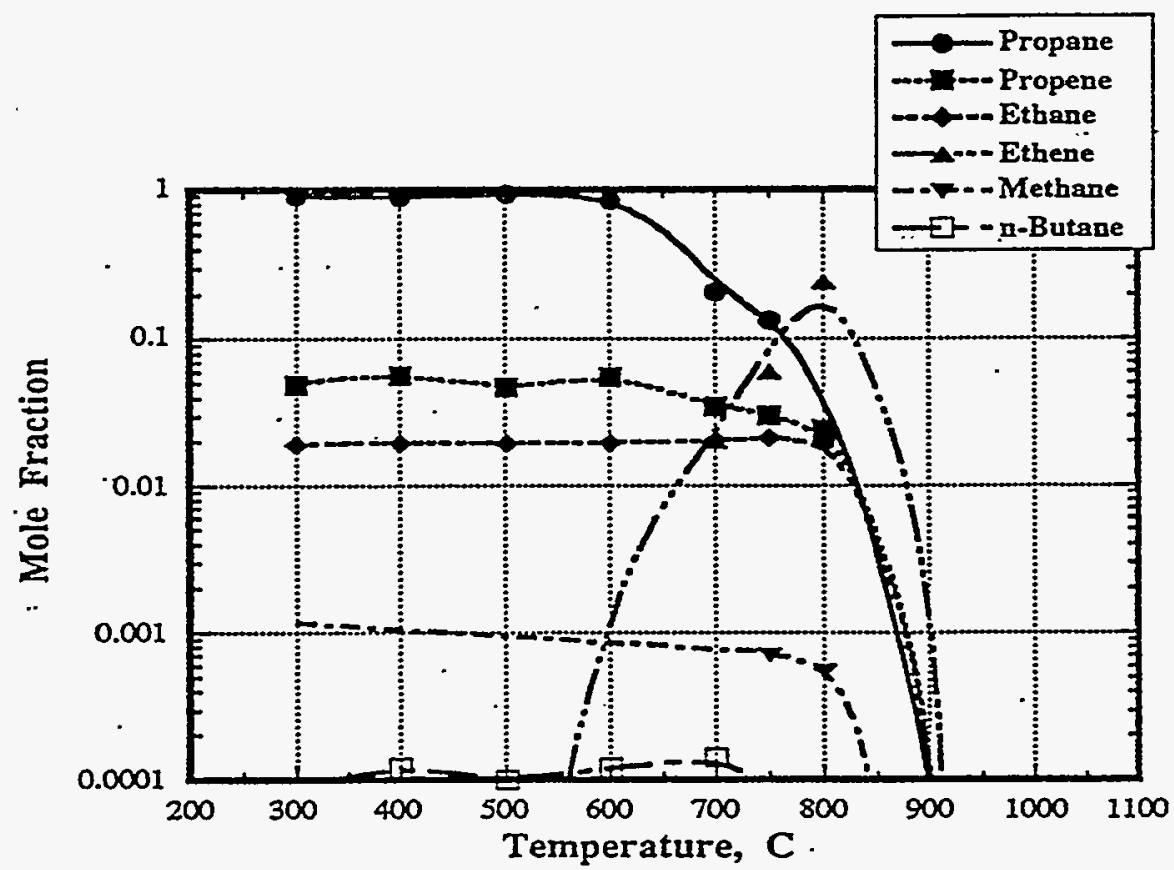

Figure 12. Organic byproduct distributions from the thermal degradation of LP gas. $\phi=1.0$. $\mathrm{t}_{\mathrm{r}}=2.0 \mathrm{~s} .\left[\mathrm{C}_{3} \mathrm{H}_{8}\right]_{0}=815 \mathrm{ppm} .\left[\mathrm{C}_{2} \mathrm{H}_{6}\right]_{0}=18 \mathrm{ppm} .\left[\mathrm{C}_{3} \mathrm{H}_{6}\right]_{0}=54 \mathrm{ppm}$. The initial concentrations of butane and heavier hydrocarbons were less than $5 \mathrm{ppm}$. 


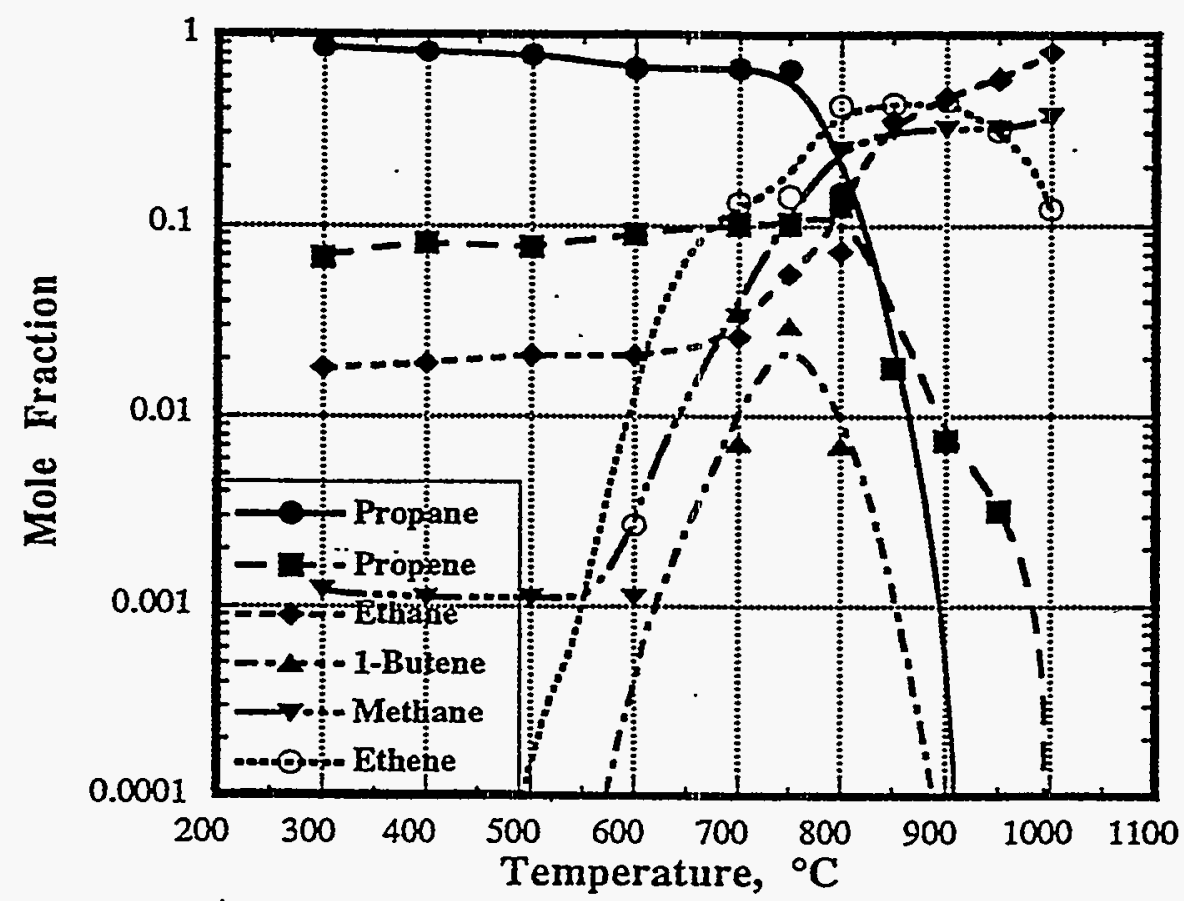

Figure 13. Organic byproduct distributions $\left(\leq \mathrm{C}_{4}\right)$ from the pyrolytic thermal degradation of LP gas. $t_{r}=2.0 \mathrm{~s}$. $\left[\mathrm{C}_{3} \mathrm{H}_{8}\right]_{0}=1180 \mathrm{ppm}$. $\left[\mathrm{C}_{2} \mathrm{H}_{6}\right] 0=25 \mathrm{ppm}$. $\left[\mathrm{C}_{3} \mathrm{H}_{6}\right] 0=80 \mathrm{ppm}$. The initial concentrations of butane and heavier hydrocarbons were less than $5 \mathrm{ppm}$.

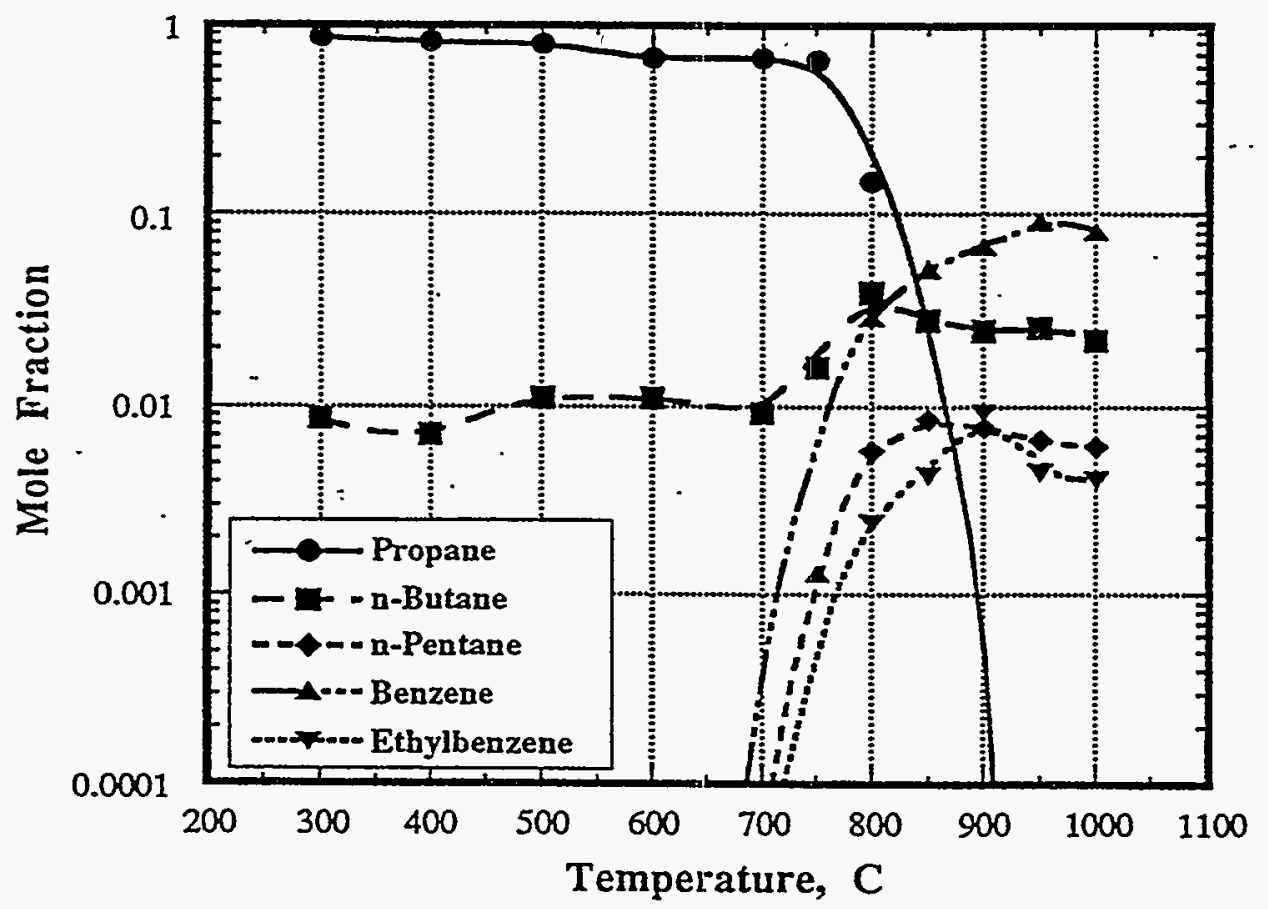

Figure 14. Organic byproduct distributions $\left(2 \mathrm{C}_{4}\right)$ from the pyrolytic thermal degradation of LP gas. $\mathrm{t}_{\mathrm{r}}=2.0 \mathrm{~s}$. $\left[\mathrm{C}_{3} \mathrm{H}_{8}\right]_{0}=1180 \mathrm{ppm}$. $\left[\mathrm{C}_{2} \mathrm{H}_{6}\right]_{0}=25 \mathrm{ppm}$. $\left[\mathrm{C}_{3} \mathrm{H}_{6}\right] 0=80 \mathrm{ppm}$. The initial concentrations of butane and heavier hydrocarbons were less than $5 \mathrm{ppm}$. 
Figure 15 presents two semi-quantitative total ion chromatograms (GC-MS detection) obtained from the stoichiometric oxidation $\left(800^{\circ} \mathrm{C}\right.$, Fig. $\left.15 \mathrm{a}\right)$ and pyrolysis $\left(1050^{\circ} \mathrm{C}\right.$, Fig. $\left.15 \mathrm{~b}\right)$ of LP gas for residence times of $1.0 \pm 0.1 \mathrm{sec}$. Qualitatively, the byproduct distributions were very similar to the natural gas studies. Under stoichiometric conditions, GC-MS detection indicated the presence of $C_{3}$ and $C_{4}$ intermediates in addition to the $C_{2}$ intermediates observed from the quantitative analysis for longer residence times. Additional reaction byproducts observed for this more sensitive, shorter residence time analysis included acetylene, 2-propenal, 1-propyne, 1,2propadiene, 1-butene, 1,3-butadiyne, 1,3-cyclopentadiene, toluene, phenylethyne, and styrene.

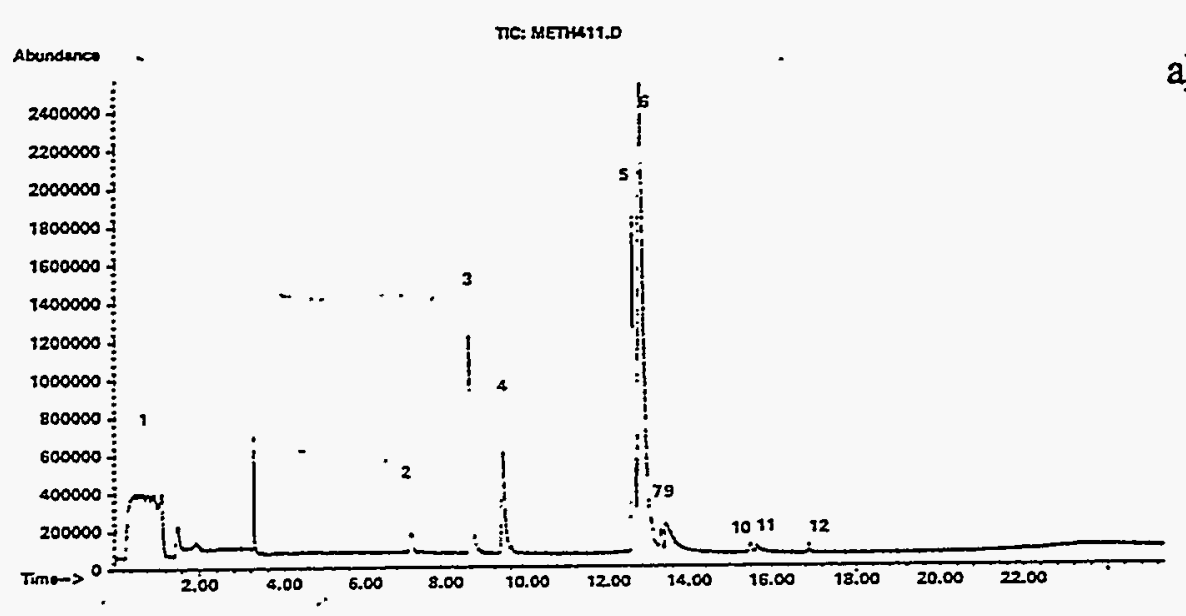

a)

b)

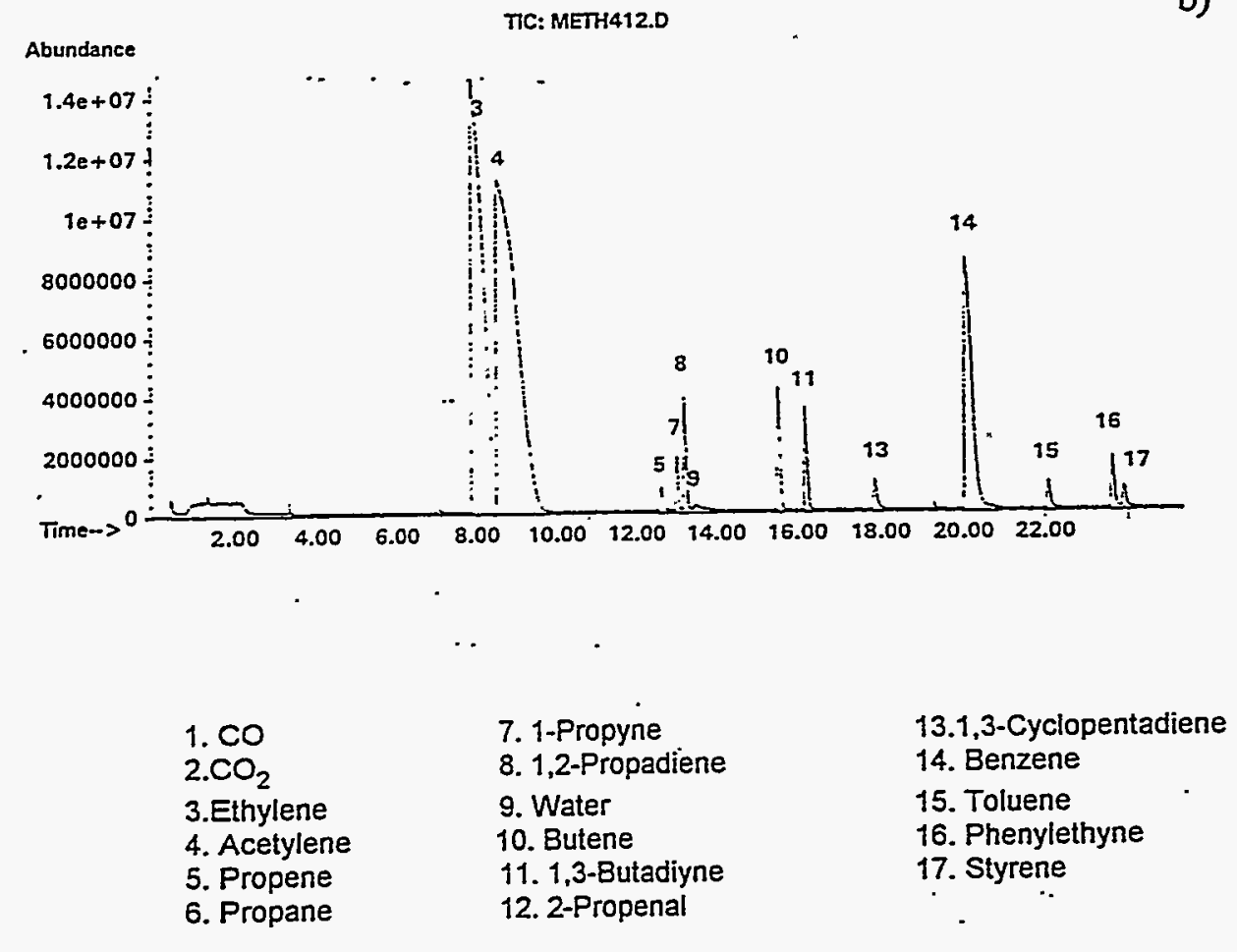

Figure 15. Total ion chromatogram of the thermal degradation of LP gas. a) $\phi=1.0, T_{r}=800^{\circ} \mathrm{C}$, $t_{r}=1.1$ sec. b) Pyrolysis, $T_{r}=1050^{\circ} C, t_{r}=0.9$ sec. See Table 3 for initial concentrations. 
The focus of these studies was quantitation of organic reaction byproducts. No attempt was made to quantitate carbon monoxide or molecular oxygen. As such, the integrity of the data is based primarily on run-to-run reproducibility and day-to-day repeatability. Based on the multiple measurements, uncertainties in quantitative byproduct yields for major and minor products were $\pm 10 \%$ and $\pm 25 \%$, respectively. In addition, carbon balances were calculated under pyrolytic conditions for natural gas and LP gas. The balances indicated that 85-90\% of the carbon was recovered as hydrocarbons. The unaccounted for carbon is attributed to higher molecular weight "soot" type material.

\section{Discussion}

This section will focus on three areas. We will initially discuss the variation of organic emissions and speciation with fuel type. We will then present calculations of indicated specific reactivities (ISR) of the organic byproducts and the effect of fuel type on ISR. We will conclude this section with a comparison of hydrocarbon speciation from our flow reactor tests versus engine tests conducted by Southwest Research Institute (SwRI). ${ }^{2}$

\section{Organic Emissions and Speciation}

The quantitative emissions data for the four alternative fuels studied are summarized in Figures 16 and 17 as non-methane hydrocarbons (NMHC) per mole of fuel, expressed as methane, for exposure temperatures of $750^{\circ} \mathrm{C}$ and $1000^{\circ} \mathrm{C}$, respectively. Methanol produced much lower yields of NMHC than ethanol, natural gas, or LP gas. Ethanol and natural gas yields were within $+25 \%$ of each other, except under pyrolysis conditions where NMHC yields from natural gas were higher. LP gas produced the largest NMHC. Yields of NMHC from LP gas were most sensitive to equivalence ratio.

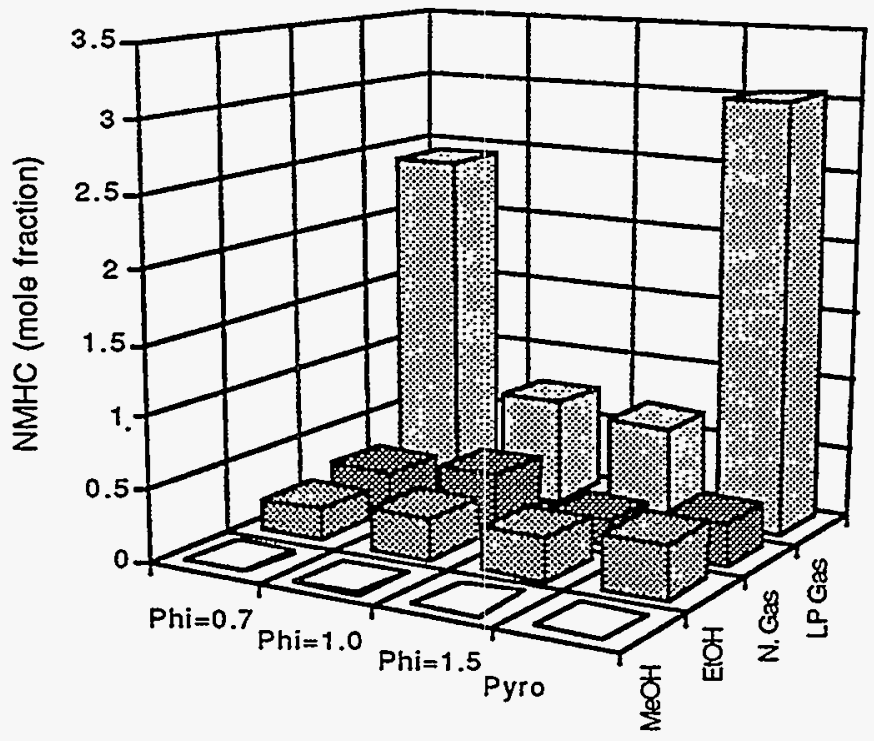

Figure 16. Yields of non-methane hydrocarbons (NMHCs) expressed as methane from methanol, ethanol, natural gas, and LP gas as a function of equivalence ratio. $T_{r}=750^{\circ} \mathrm{C}$. $t_{r}=2.0 \mathrm{~s}$. See Table 3 for initial tuel concentrations. 


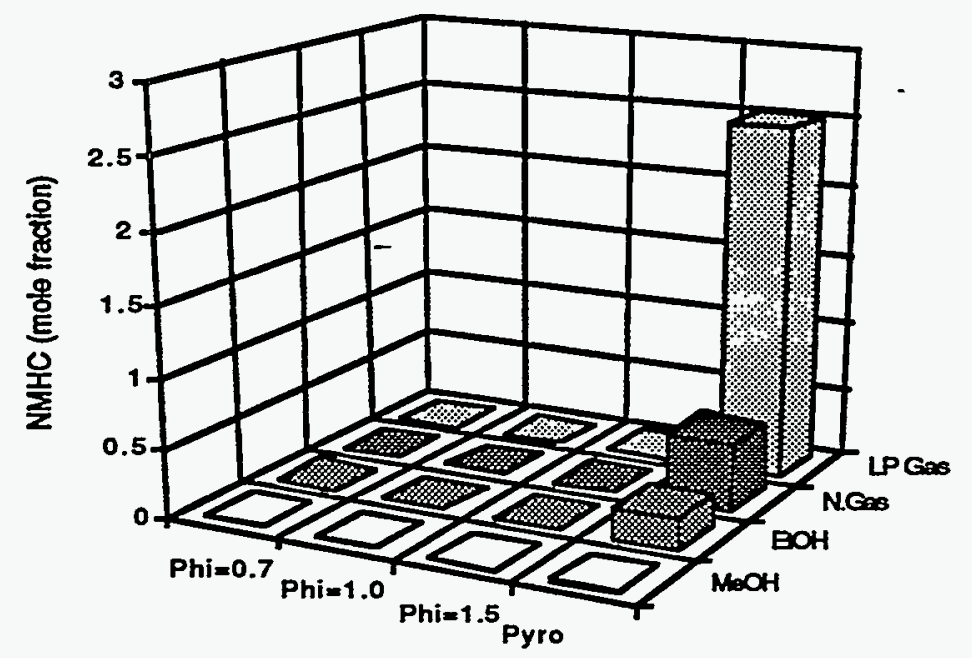

Figure 17. Yields of non-methane hydrocarbons (NMHCs) expressed as methane from methanol, ethanol, natural gas, and LP gas as a function of equivalence ratio. $T_{r}=1000^{\circ} \mathrm{C}$. $t_{r}=2.0 \mathrm{~s}$. See Table 3 for Initlal fuel concentrations.

Figure 18 presents data for total oxygenates (mole fraction) observed from the four alternative fuels studied at a temperature of $750^{\circ} \mathrm{C}$. Ethanol produced the only measurable yields of oxygenates, with peak values observed under stoichiometric reaction conditions. Acetaldehyde and a trace of acetic acid were the observed oxygenate emissions for ethanol. Total oxygenates were below detection limits for each fuel at a temperature of $1000^{\circ} \mathrm{C}$. No oxygenates were observed from the thermal degradation of natural gas and LPG. Oxygenate formation from methanol and ethanol was very sensitive to exposure temperature. At slightly lower temperatures, i.e. $700^{\circ} \mathrm{C}$, the total oxygenate mole fraction approached 0.4 for ethanol and ranged from 0.3 to 0.8 for methanol, depending on equivalence ratio. The sensitivity to exposure temperature near $750^{\circ} \mathrm{C}$ is indicative of the relative ease of conversion (oxidation) of formaldehyde, acetaldehyde, and other oxygenates compared to unsaturated hydrocarbons.

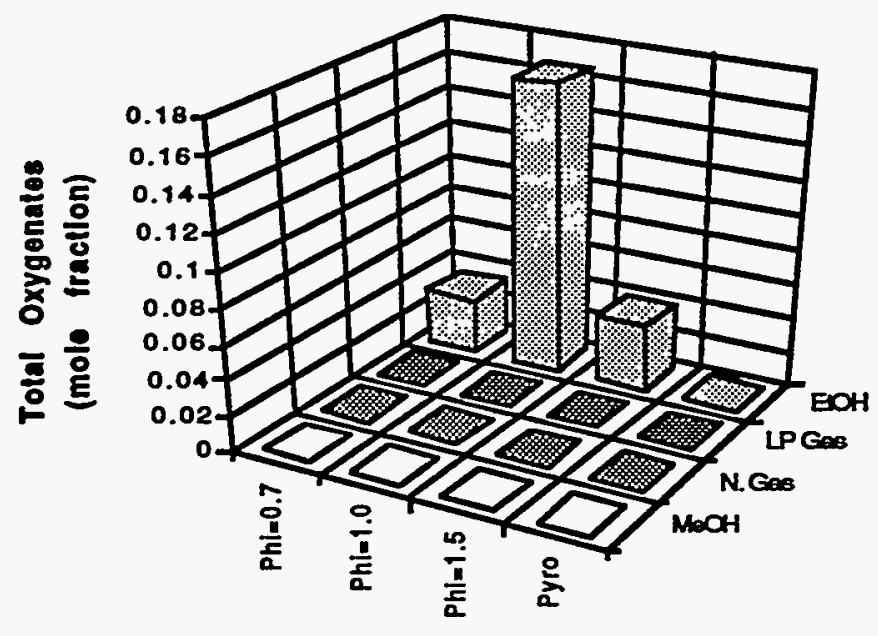

Figure 18. Yields of total oxygenates (mole fractlon) from methanol, ethanol, natural gas, and LP gas as a function of equivalence ratio. $T_{r}=750^{\circ} \mathrm{C}$. $t_{r}=2.0 \mathrm{~s}$. See Table 3 for Intial fuel concentration. 
The semi-quantitative GC-MS data have been used to examine more closely the effect of fuel structure on organic emissions. The results are presented in Figs. 19 and 20 for stoichiometric oxidation and pyrolysis conditions, respectively. Unreacted fuel has not been included in this analysis. A temperature of $800^{\circ} \mathrm{C}$ was arbitrarily selected to compare the emissions. This temperature does bear some significance to engine emissions, however, as it is believed to roughly correspond to the low temperature limit of post-combustion conversion of residual fuel in the boundary layers of the engine cylinder. ${ }^{5}$ The data demonstrate a significant effect of fuel type on emissions. The most dramatic effect was the lack of any detectable organic emissions from the stoichiometric oxidation of methanol. The remaining fuels produce significant emissions, however, yields of light hydrocarbons, ox.ygenates, and aromatic compounds varied significantly. Only recently has it been demonstrated that fuel structure has a significant impact on organic emissions 6,7 . This study, the first direct comparison for these four alternative fuels, results in the same conclusion.

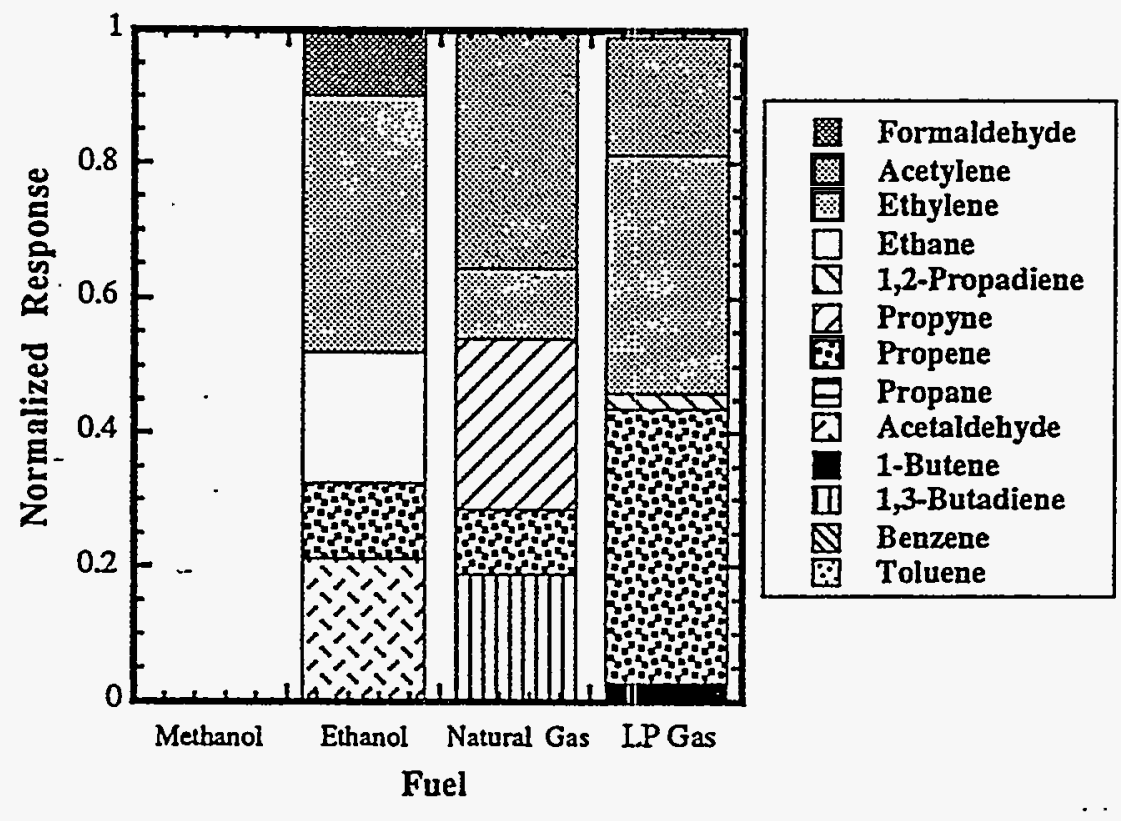

Figure 19. Normalized, semi-quantitative organic byproduct distributions as a function of fuel type. $\phi=1, T_{\mathrm{r}}=800^{\circ} \mathrm{C}, \mathrm{t}_{\mathrm{r}}=1.0 \pm 0.1 \mathrm{sec}$. For initial fuel concentration, see Table 3 . 


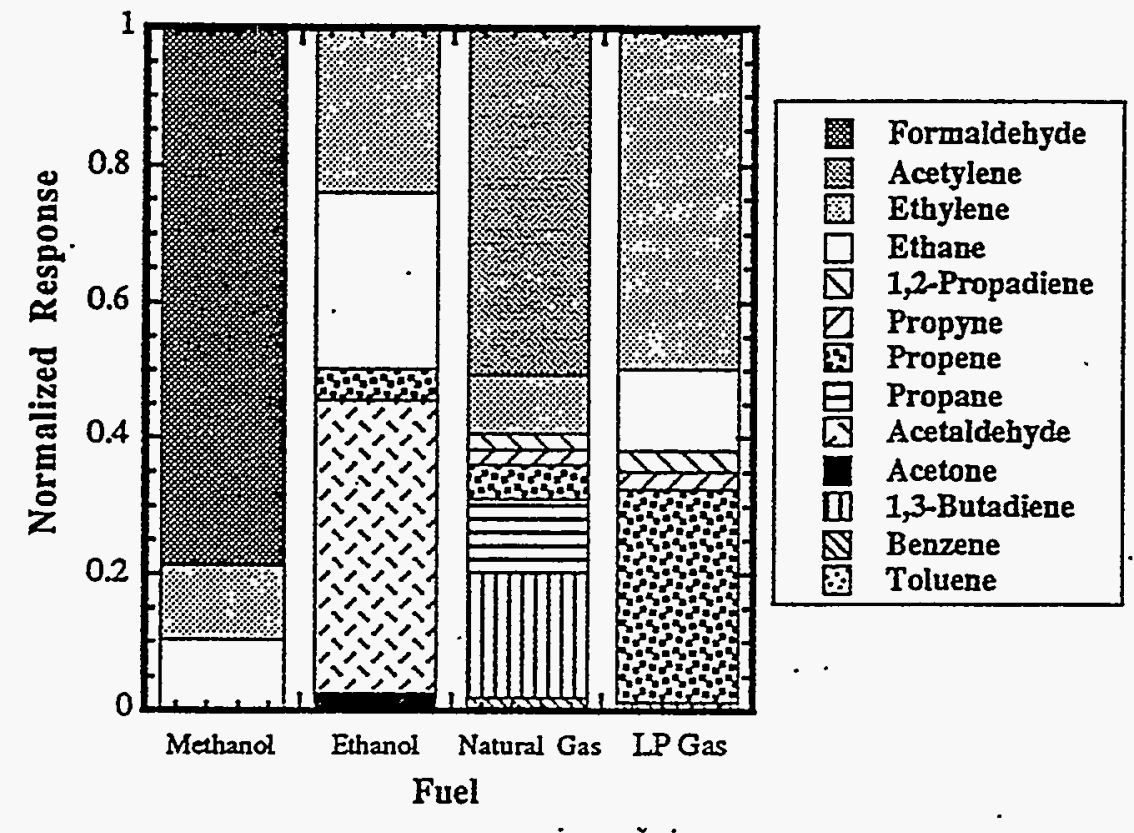

Figure 20. Normalized, semi-quantitative organic byproduct distributions as a function of fuel type. Pyrolysis, $T_{\mathrm{r}}=800^{\circ} \mathrm{C}, \mathrm{t}_{\mathrm{r}}=1.0 \pm 0.1 \mathrm{sec}$. For initial fuel concentration, see Table 3 .

\section{Atmospheric Reactivity Determinations}

In order to assess the atmospheric impact of emissions, the specific reactivity (SR) of the exhaust gas was calculated for each fuel. SR is defined as the grams of ozone produced in the atmosphere per gram of $\mathrm{HC}$ emissions from a fuel. ${ }^{8} \mathrm{SR}$ is a function of maximum incremental reactivity (MIR), which define the atmospheric reactivity of each exhaust species. MIR factors have been established by the California Air Resources Board (CARB). ${ }^{9}$ Alkanes have very low MIR values while alkenes and dienes have generally higher MIR values. MIR values of aromatic compounds are in general less than MIRs of alkenes, with alkyl-substituted aromatics being larger than unsubstituted aromatics but less than alkenes. Indicated specific reactivity (ISR), which is a measure of grams of the $\mathrm{O}_{3}$ formation by photochemical reaction per mole of fuel, was also calculated for the different fuels investigated. ISR values were obtained by multiplying SR by the grams of hydrocarbon emissions per mole of fuel. ISR values were used in this analysis to conviently compare the reactivity of the different fuels since the byproduct concentrations were expressed in mole fraction.

Calculated ISR's for all four fuels as a function of equivalence ratio are presented in Figs. 21 and 22 for exposure temperatures of $750^{\circ} \mathrm{C}$ and $1000^{\circ} \mathrm{C}$, respectively. For methanol, ethanol, and natural gas, ISR's exhibited similar trends to the NMHC emissions. This is mainly due to the fact that 1) oxygenates have not been assigned incremental reactivity factors, and 2) compounds - with high incremental reactivity factors, e.g., ethene, propene, were observed in comparable yields from the thermal degradation of each fuel. Methanol had the lowest ISR, essentially zero, regardless of equivalence ratio or exposure temperature. ISR's for natural gas were significantly less than ethanol for all equivalence ratios at $750^{\circ} \mathrm{C}$. At $1000^{\circ} \mathrm{C}$, ISR's for ethanol and natural gas were comparable under pyrolytic conditions. The fuel with the largest ISR was LP gas. However, the difference in the ISR's of ethanol and LP gas was much smaller than the difference 
in NMHC. This indicates that organic byproducts from the thermal degradation of LP gas contained a smaller fraction of alkenes compared to ethanol. At $1000^{\circ} \mathrm{C}$ and for equivalence ratios of 0.7, 1.0, and 1.5, the ISR's for ethanol, natural gas, and LP gas were essential zero.

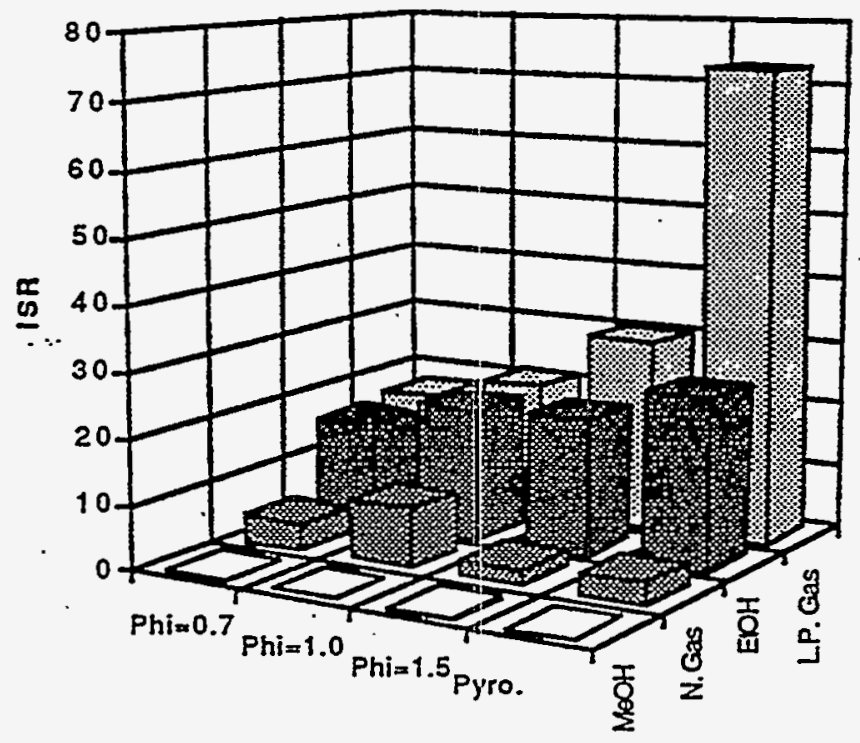

Figure 21. Indicated specific reactivity (ISR) determinations for methanol, ethanol, natural gas, and LP gas as a function of equivalence ratio. $T_{r}=750^{\circ} \mathrm{C} . t_{r}=2.0 \mathrm{sec}$. Initial fuel concentration: see Table 3.

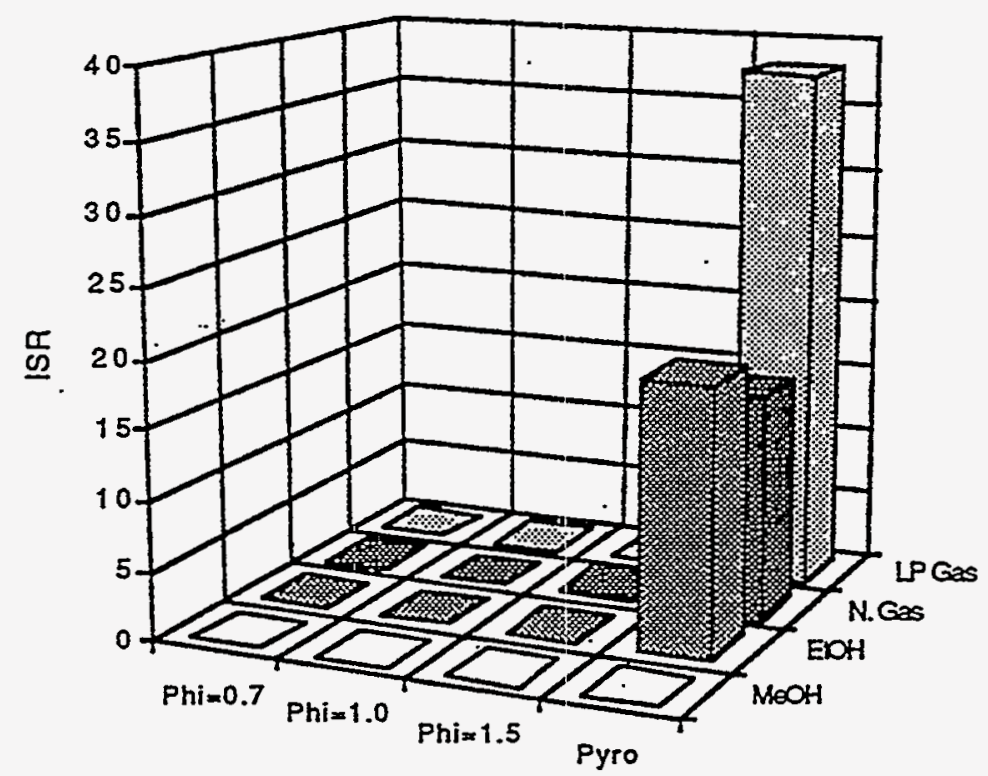

Figure 22. Indicated specific reactivity (ISR) determinations for methanol, ethanol, natural gas, and $L P$ gas as a function of equivalence ratio. $T_{T}=1000^{\circ} \mathrm{C} . t_{r}=2.0 \mathrm{sec}$. Initial fuel concentration: see Table 3. 


\section{Organic Speciation: Flow Reactor Experiments versus Engine Tests}

In this section, we present a comparison of observed products from the flow reactor experiments with the recent engine tests of these alternative fuels conducted by Southwest Research Institute. ${ }^{2}$ It is instructive to begin with a simple, qualitative comparison. The results for the alcohol fuels and the hydrocarbon fuels are summarized in Tables 4 and 5, respectively.

Table 4. Emissions Comparison of Alcohol Alternative Fuels.

\begin{tabular}{||l|c|c|c|c||}
\hline \multicolumn{1}{|c|}{ Quantified Emission Byproduct } & \multicolumn{2}{|c|}{ Methanol } & \multicolumn{2}{c|}{ Ethanol } \\
\hline & $\begin{array}{c}\text { Reactor } \\
\text { Test }\end{array}$ & $\begin{array}{c}\text { Engine } \\
\text { Test }^{2}\end{array}$ & $\begin{array}{c}\text { Reactor } \\
\text { Test }\end{array}$ & $\begin{array}{c}\text { Engine } \\
\text { Test }^{2}\end{array}$ \\
\hline Air Toxics & & & & \\
\hline Formaldehyde & $\mathrm{X}$ & $\mathrm{X}$ & $\mathrm{X}$ & $\mathrm{X}$ \\
\hline Acetaldehyde & & $\mathrm{X}$ & $\mathrm{X}$ & $\mathrm{X}$ \\
\hline Benzene & & $\mathrm{X}$ & $\mathrm{X}$ & $\mathrm{X}$ \\
\hline $1,3-$ Butadiene & & $\mathrm{X}$ & & $\mathrm{X}$ \\
\hline Other Organics (excluding Methane) & & & & \\
\hline Ethane & & & & $\mathrm{X}$ \\
\hline Ethene & $\mathrm{X}$ & & $\mathrm{X}$ & $\mathrm{X}$ \\
\hline Acetylene & $\mathrm{X}$ & $\mathrm{X}$ & $\mathrm{X}$ & $\mathrm{X}$ \\
\hline Propene & & $\mathrm{X}$ & $\mathrm{X}$ & $\mathrm{X}$ \\
\hline Acetic Acid & & & $\mathrm{X}$ & \\
\hline Toluene & & $\mathrm{X}$ & & \\
\hline
\end{tabular}

The quantified emission byproducts for the alcohol fuels were remarkably similar. For methanol, the organic products in common with both sets of data were formaldehyde, ethene, and acetylene. For ethanol, the organic byproducts in common with both sets of data were formaldehyde, acetaldehyde, benzene, ethane, ethene, and acetylene. The most significant differences in the comparisons were the lack of detection of the "air toxics" acetaldehyde, benzene, and 1,3-butadiene from the flow reactor studies of methanol degradation and the lack of detection of 1,3-butadiene from the flow reactor studies of ethanol degradation.

The quantified emission byproducts for the hydrocarbon fuels showed greater disagreement. Organic products in common with both fuels and both sets of studies were benzene, ethane, ethene, acetylene, propane, and propene. The flow reactor studies indicated significant formation of heavier hydrocarbons $\left(\mathrm{C}_{3}, \mathrm{C}_{4}, \mathrm{C}_{5}, \mathrm{C}_{7}\right.$, and $\mathrm{C}_{8}$ species), particularly under oxygenfree pyrolysis conditions. These products, excluding benzene were not observed in the engine tests. Another notable difference was the detection of formaldehyde from the engine tests. Formaldehyde was not observed in the flow reactor experiments, although trace formation of acetaldehyde and 2-propenal were observed. 
Table 5. Emissions Comparison of Hydrocarbon Alternative Fuels.

\begin{tabular}{||l|c|c|c|c||}
\hline & \multicolumn{2}{|c|}{ Natural Gas } & \multicolumn{2}{c|}{ L.P. Gas } \\
\hline & $\begin{array}{c}\text { Reactor } \\
\text { Test }\end{array}$ & $\begin{array}{c}\text { Engine } \\
\text { Test }^{2}\end{array}$ & $\begin{array}{c}\text { Reactor } \\
\text { Test }\end{array}$ & $\begin{array}{c}\text { Engine } \\
\text { Test }^{2}\end{array}$ \\
\hline Air Toxics & & & & \\
\hline Formaldehyde & & & & \\
\hline Acetaldehyde & & $\mathrm{X}$ & $\mathrm{X}$ & $\mathrm{X}$ \\
\hline Benzene & $\mathrm{X}$ & $\mathrm{X}$ & $\mathrm{X}$ & $\mathrm{X}$ \\
\hline 1,3-Butadiene & $\mathrm{X}$ & $\mathrm{X}$ & & $\mathrm{X}$ \\
\hline Other Organics (excluding Methane) & & & & \\
\hline Acetic Acid & & & & \\
\hline Ethane & & & & \\
\hline Ethene & $\mathrm{X}$ & $\mathrm{X}$ & & $\mathrm{X}$ \\
\hline Acetylene & $\mathrm{X}$ & $\mathrm{X}$ & $\mathrm{X}$ & $\mathrm{X}$ \\
\hline Propane & $\mathrm{X}$ & $\mathrm{X}$ & $\mathrm{X}$ & $\mathrm{X}$ \\
\hline Propene & $\mathrm{X}$ & $\mathrm{X}$ & $\mathrm{X}$ & $\mathrm{X}$ \\
\hline Propyne & $\mathrm{X}$ & & $\mathrm{X}$ & \\
\hline 1,2-Propadiene & $\mathrm{X}$ & & $\mathrm{X}$ & \\
\hline 2-Propenal & $\mathrm{X}$ & & & \\
\hline n-Butane & $\mathrm{X}$ & & & \\
\hline 1-Buten-3-yne & & & $\mathrm{X}$ & \\
\hline 1,3-Butadiyne & $\mathrm{X}$ & & $\mathrm{X}$ & \\
\hline 1-Butene & & & & \\
\hline 1-Pentene & & & & \\
\hline 1,3-Cyclopentadiene & & & $\mathrm{X}$ & \\
\hline Toluene & $\mathrm{X}$ & & $\mathrm{X}$ & \\
\hline Ethylbenzene & $\mathrm{X}$ & & $\mathrm{X}$ & \\
\hline Phenylethyne & & & $\mathrm{X}$ & \\
\hline Styrene & & & & \\
\hline \hline
\end{tabular}

Figs. 23 and 24 presents a quantitative comparison of speciated NMOG emissions from the flow reactor experiments and the engine tests for the alcohol fuels and the hydrocarbon fuels, respectively. The exposure temperature of the stoichiometric oxidation flow reactor tests were varied over a considerable temperature range $\left(500^{\circ} \mathrm{C}-900^{\circ} \mathrm{C}\right)$ to give the best overall agreement with engine out, no catalyst emissions tests. The results for methanol were very good for flow reactor exposures of $600^{\circ} \mathrm{C}$. The comparison for ethanol did not provide a good comparison for any temperature, with $500^{\circ} \mathrm{C}$ providing the best overall agreement. The major deviation was the larger amount of unreacted ethanol observed in the engine tests. A higher exposure temperature $\left(750^{\circ} \mathrm{C}\right)$ was required to provide the best overall comparison of engine tests and flow reactor experiments for natural gas and LP gas. The major deviation in these comparisons was the observation of formaldehyde and acetaldehyde in the engine tests. 
Methanol

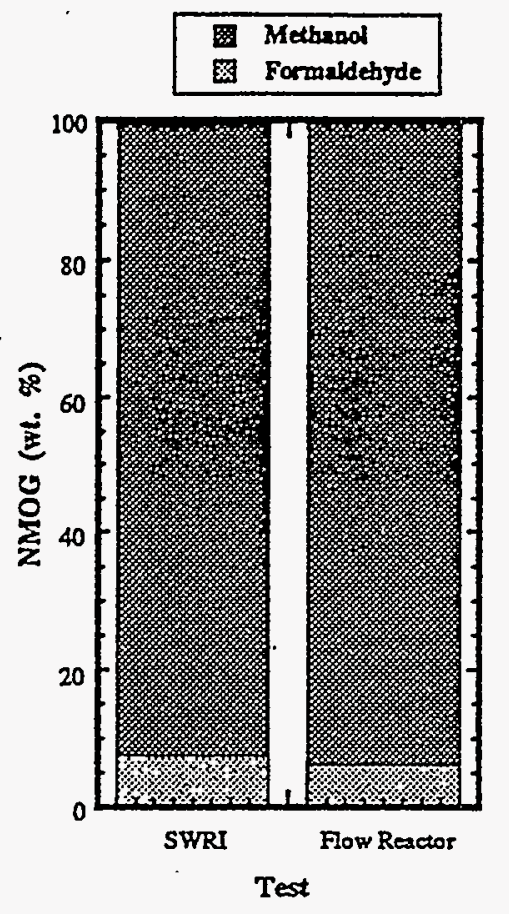

\section{Ethanol}

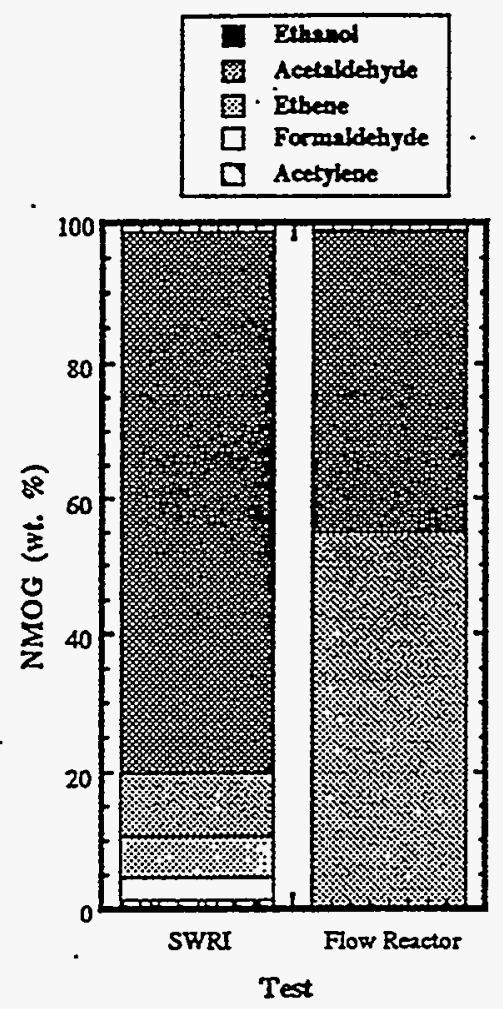

Figure 23. Comparison of NMOG byproduct distributions from methanol and ethanol from SWRI engine tests ${ }^{2}$ and UDRI flow reactor experiments. Engine data are engine out, no catalyst emissions. Flow reactor data were obtained for the following conditions: Methanol, $\phi=1, T_{r}=$ $600^{\circ} \mathrm{C}, \mathrm{t}_{\mathrm{r}}=2.0 \mathrm{sec}$; Ethanol, $\phi=1.0, \mathrm{~T}_{\mathrm{r}}=500^{\circ} \mathrm{C}, \mathrm{t}_{\mathrm{r}}=2.0 \mathrm{sec}$. See Table 3 for initial fuel concentrations. 
Natural Gas

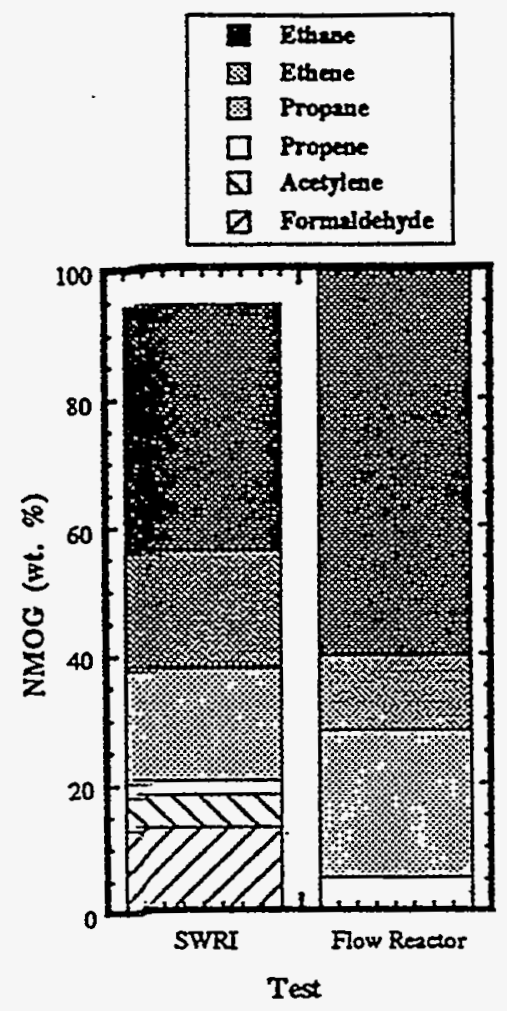

LP Gas

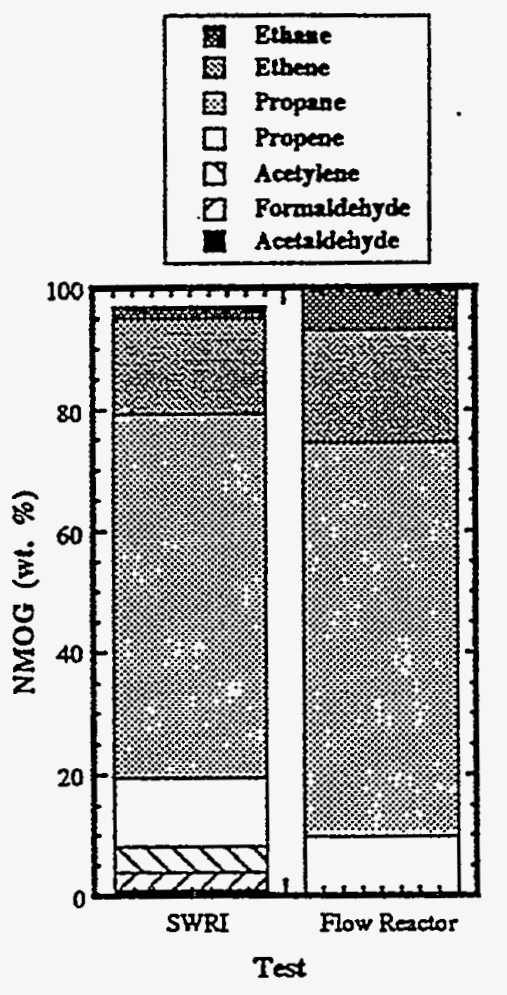

Figure 24. Comparison of NMOG byproduct distributions from natural gas and LP gas from SWRI engine tests ${ }^{2}$ and UDRI flow reactor experiments. Engine data are engine out, no catalyst emissions. Flow reactor data were obtained for the following conditions: Natural gas, $\phi=1, \mathrm{~T}_{\mathrm{T}}=$ $750^{\circ} \mathrm{C}, \mathrm{t}_{\mathrm{r}}=2.0 \mathrm{sec} ; \mathrm{LP}$ gas, $\phi=1.0, \mathrm{~T}_{\mathrm{r}}=750^{\circ} \mathrm{C}, \mathrm{t}_{\mathrm{r}}=2.0 \mathrm{sec}$. See Table 3 for initial fuel concentrations.

This comparison was not conducted to show strict quantitative agreement because of the fluid mechanical aspects of the combustion process which are not adequately addressed in flow reactor studies. ${ }^{5}$ However, the results do show good correlations in the relative yields of several species, particularly the light hydrocarbons. The other byproducts, that did not show quantitative agreement were observed. However, they were observed under different conditions. These results denonstrate the importance of gas-phase chemical kinetics but also suggest the importance of developing better fluid dynamic models of the engine and exhaust systems.

For the hydrocarbon fuels, good correlations were obtained at temperatures that may correspond to the boundary layers of engine cylinders. ${ }^{5}$ The even lower temperatures required to provide a tetter comparison for the alcohol fuels suggests that severe thermal quenching failure modes 5 played a larger role in creating emissions from engine tests of the alcohol fuels than the hydrocarbon fuels. 


\section{Task 2 - Elementary Reaction Kinetic Studies of $\mathrm{OH}$ with Exhaust Products over an Extended Temperature Range}

The objective of these experiments is to measure elementary reaction rate coefficients for the reaction of $\mathrm{OH}$ radicals with methanol, ethanol, methane, propane, and representative combustion byproducts of these fuels at temperatures relevant to tropospheric chemistry and the combustion of these compounds, i.e., 240 to $1000 \mathrm{~K}$. Rate coefficients are being measured with a single apparatus using a modified laser photolysis/laser-induced fluorescence (LP/LIF) technique.

The experiments discussed in the ensuing paragraphs are attempting to address the following issues:

1) elucidation of structure-activity-relationships for reactions of alternative fuels and exhaust byproducts with $\mathrm{OH}$;

2) identification of multiple mechanisms of reaction and any change in mechanism with temperature;

3) improvement of application of transition state theory formalism to modeling of bimolecular reactions over extended temperature ranges;

4) development of improved detailed, elementary reaction kinetic models of alternative fuel combustion; and

5) identification of systematic error in previous low temperature measurements and improvement of the alternative fuel-OH reaction kinetic data base pertaining to tropospheric lifetimes.

To address these issues, we are utilizing a refined LP/LIF technique for the measurement of $\mathrm{OH}$-alternative fuel reaction kinetics over an extended temperature range. The major advantages of this technique as described in the following paragraphs, are:

1) capability to measure reaction rate constants over an extended temperature range using a single apparatus;

2) generation of a clean source of $\mathrm{OH}$ radicals;

3) capability of atmospheric pressure measurements;

4) extensive purification and analysis of all reactants;

5) capability to thoroughly analyze potential photolysis-based secondary reactions.

\section{Experimental Approach}

To obtain $\mathrm{OH}$-alternative fuel kinetics data over extended temperature ranges, a refined LP/LIF technique (cf. Fig. 25) is being employed. This apparatus has been described previously in detail; ${ }^{10-12}$ an abbreviated description follows.

A resistively heated, fused silica optical test cell permits data to be acquired from room temperature to $\sim 1000 \mathrm{~K}$. The gas transport time, from the onset of heating until the reaction volume is reached, based on a linear gas velocity of $4 \mathrm{~cm} / \mathrm{s}$, is $\sim 0.875$ seconds . Mutually perpendicular axes of the cell permit irradiation of the reaction volume by the photolysis and probe lasers and detection of laser-induced $\mathrm{OH}$ fluorescence. Data are taken at a $10 \mathrm{~Hz}$ rate coinciding with the firing of the lasers. A gas velocity of $\geq 4 \mathrm{~cm} / \mathrm{sec}$ traverses the cell to ensure that each photolysis/probe pulse pair encounters a fresh reaction volume, thus reducing the buildup of reaction products. The cell temperature is monitored by a thermocouple placed $\sim 3 \mathrm{~mm}$ below the reaction zone. A temperature controller (Omega: $4001 \mathrm{KC}$ ) is used to maintain the desired cell temperature $( \pm 2 \mathrm{~K})$ during experiments. Measurements from a second retractable thermocouple 
inserted into the gas flow indicate no more than a $\pm 3 \mathrm{~K}$ temperature variation across the reaction volume.

Hydroxyl radicals are generated by the photolysis of nitrous oxide $\left(\mathrm{N}_{2} \mathrm{O}\right)$ in the presence of water vapor. The photolysis laser is a pulsed ( $10 \mathrm{~Hz}$ ) ArF excimer laser (Questek: 2840) operating at a wavelength of $193.3 \mathrm{~nm}$. Photolysis intensities for an experiment range from $3-8 \mathrm{~mJ} \mathrm{~cm}^{-2}$. $\mathrm{N}_{2} \mathrm{O}$ photolysis produces excited $\mathrm{O}\left({ }^{1} \mathrm{D}\right)$ atoms on a time scale of $\sim 20 \mu \mathrm{s} ; \mathrm{O}\left({ }^{1} \mathrm{D}\right)$ atoms are rapidly converted to ground state $\mathrm{OH}$ by reaction with $\mathrm{H}_{2} \mathrm{O}$ :
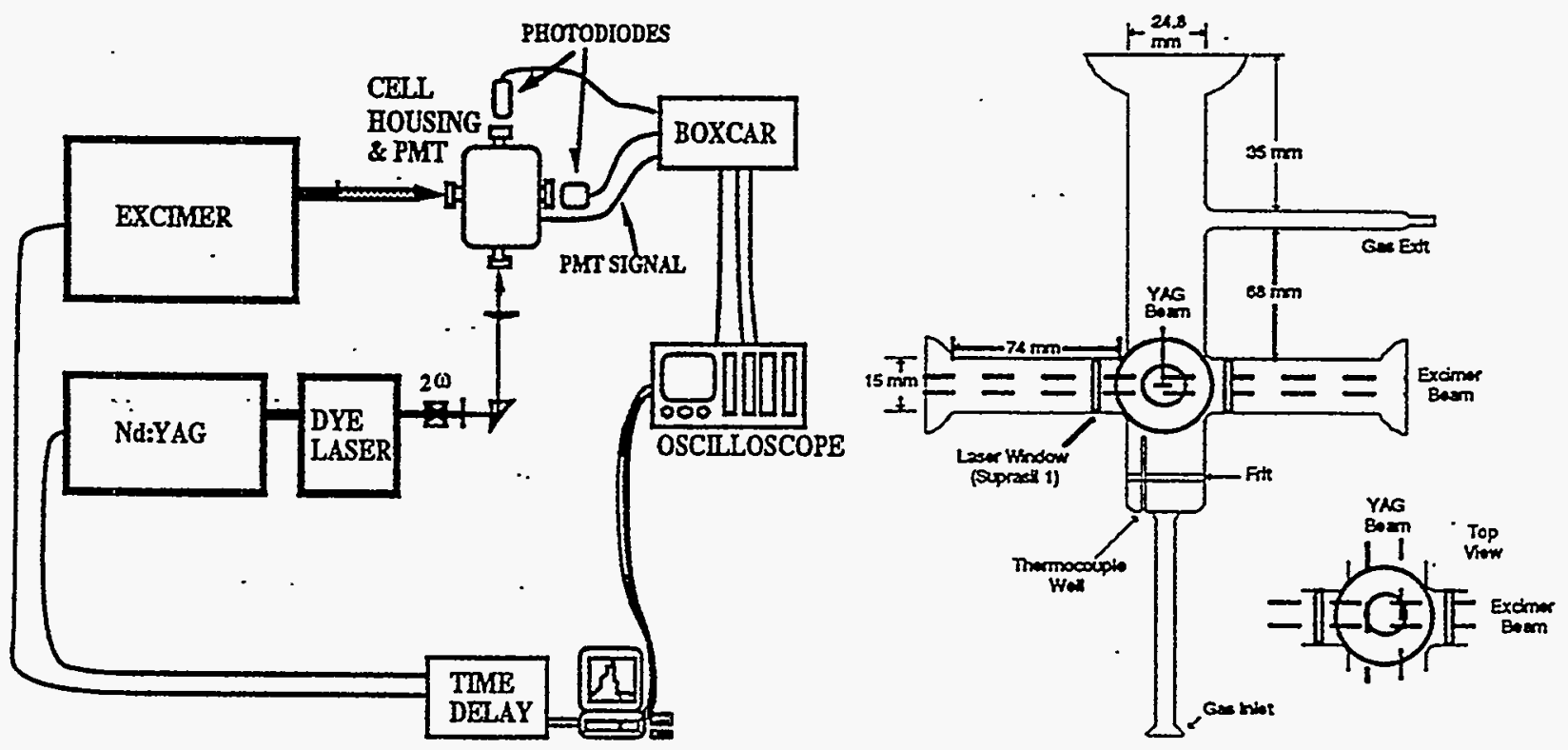

Figure 25. Schematic of OH LP/LIF system (left) and high temperature optical test cell (right).

$$
\begin{gathered}
\mathrm{N}_{2} \mathrm{O}+\mathrm{hv}(193 \mathrm{~nm})-\mathrm{N}_{2}+\mathrm{O}\left({ }^{1} \mathrm{D}\right) \\
\mathrm{O}\left({ }^{\mathrm{l} D}\right)+\mathrm{H}_{2} \mathrm{O} \rightarrow-\cdots 2 \mathrm{OH} .
\end{gathered}
$$

$\mathrm{H}_{2} \mathrm{O}$ concentrations are maintained in excess of $\mathrm{N}_{2} \mathrm{O}$ (typically 20:1) to ensure complete conversion of $\mathrm{O}$ atoms to $\mathrm{OH}$ (absolute concentrations, independent of temperature, are $\mathrm{H}_{2} \mathrm{O}: 3.2 \mathrm{x}$ $10^{15}$ molec $\mathrm{cm}^{-3}$ and $\mathrm{N}_{2} \mathrm{O}: 1.1 \times 10^{14} \mathrm{molec} \mathrm{cm}^{-3}$ ). Once created, the relative $\mathrm{OH}$ population is monitored by laser-induced fluorescence. The probe beam system consists of a frequency-doubled pulsed (10 Hz) Nd:Yag pumped dye laser (Quanta-Ray: DCR-1/PDL-2). This tandem laser system is used to generate $\sim 500 \mathrm{~mJ}$ pulses at $282.1 \mathrm{~nm}$ with the use of an external second harmonic generation KDP crystal. Extensive experimentation has shown no evidence of drift/variability in the probe laser intensity after thermal equilibration ( $\leq 1 \mathrm{~min}$.) of the KDP crystal. This wavelength is used to excite the $\left(A\left({ }^{2} \Sigma^{+}\right), v^{\prime}=1, J=5 / 2<\ldots X(2 \Pi), v^{\prime \prime}=0, J=5 / 2\right)$ transition of the $O H$ radical. Broad-band $\mathrm{OH}$ fluorescence is collected at $306 \mathrm{~nm}$, corresponding to the $0-0$ vibronic transition in emission.

Helium is used as diluent and carrier gas for the $\mathrm{OH}$ precursors and substrate. Each gas is separately metered using differential flow controllers (Porter Instr.: VCD-1000) and thoroughly mixed in a pyrex manifold. Dilute organic vapor reactants are introduced downstream of the manifold using a calibrated, gas-tight, teflon-sealed, syringe and syringe pump (Sage Instruments: 341B). Calibrations are obtained (and flow rates checked after each experiment) using the soap 
bubble meter method. With this procedure, flow rates are measured within $\pm 0.3 \%$. Flow rates of all aspects of this sample delivery system are repeatable to within $\pm 2 \%$.

Hydroxyl fluorescence is collected by a quartz lens mounted at the top of the test cell and focused on the photocathode of a photomultiplier tube (RCA: 31034A) that is calibrated for linearity. A bandpass filter (Acton Research: $308.5 \mathrm{~nm}, 11 \mathrm{~nm}$ FWHM) and 2 colored glass filters (Schott: UG-11, WG-305) are used to reduce background signal levels. The output current from the PMT is fed into a boxcar integrator (Stanford Research Systems Model 255) where it is amplified and signal averaged. Computerized data collection, storage, reduction, and statistical propagation of error analysis of random errors are performed after each set of experiments. The temporal profiles of $\mathrm{OH}$ are determined by measuring the LIF signal at various delay times, typically 200-20,000 $\mu \mathrm{sec}$ between the photolysis and probe laser pulse. A computer controlled time delay circuit is used to step the pump and probe lasers in $200 \mu$ s intervals. Photodiodes are used to monitor the pump and probe beam laser intensities. This data is then used to correct the fluorescence signal for shot to shot variability. There has been no evidence of drift in the pump or probe laser intensity and shot to shot variability is less than $5 \%$ for each laser. Signal averaging consists of 10-30 laser shots at each time delay, which further corrects for any laser or PMT instability.

\section{Data_Reduction}

All experiments are performed under pseudo-first-order kinetic conditions. The variation in $\mathrm{OH}$ number density as a function of photolysis laser intensity is estimated by the following relation which can be readily derived from the 2-step $\mathrm{OH}$ production sequence described above:

$$
[\mathrm{OH}] \approx 2[\mathrm{O}]=\left(1-\left[\mathrm{N}_{2} \mathrm{O}\right] /\left[\mathrm{N}_{2} \mathrm{O}\right] \mathrm{O}\right)\left[\mathrm{N}_{2} \mathrm{O}\right]_{0}
$$

where $\left[\mathrm{N}_{2} \mathrm{O}\right] /\left[\mathrm{N}_{2} \mathrm{O}\right] 0=\exp \left(-\mathrm{k}_{\text {exe }} t\right)$ and $\mathrm{k}_{\text {exe }}=3.71 \times 10^{-6} \varepsilon \phi(\mathrm{P} / \mathrm{A}) .^{2}$ Initial reactant concentrations range from $5-50 \times 10^{13} \mathrm{molec} \mathrm{cm}^{-3}$, in great excess of initial $\mathrm{OH}$ concentrations $\left(0.2-1.0 \times 10^{11}\right.$ molec $\left.\mathrm{cm}^{-3}\right)$. OH decays are obtained over at least 3 decay lifetimes by signal averaging $\sim 1000-5000$ laser pulses per decay.

Impurities in OH precursors, organic reactants, organic reactant photolysis, and secondary reactions due to production of reactive radical and stable species all pose interferences to the accurate measurement of the absolute bimolecular rate constant under these experimental conditions. An overall differential rate equation governing the disappearance of $\mathrm{OH}$ as a function of time includes the following terms:

$$
\begin{aligned}
& \quad \cdot \frac{-d[\mathrm{OH}]}{d t}=k_{d i r}[\mathrm{OH}]+k_{\mathrm{red}}\left[\mathrm{OH}^{2}\right]+k_{i d}[\mathrm{OH}][\mathrm{imp}, \mathrm{c}]+k_{i r}[\mathrm{OH}][\mathrm{imp}, \mathrm{s}] \\
& +k_{\text {ORGANIC }}[\mathrm{OH}][\mathrm{ORGANIC}]+k_{t r}[\mathrm{OH}][\mathrm{TR}]+k_{\mathrm{pr}}[\mathrm{OH}][\mathrm{PR}]+k_{\mathrm{sed}}[\mathrm{OH}][\mathrm{SEC}]
\end{aligned}
$$

where: $\mathrm{k}_{\text {dif }}=\mathrm{OH}$ diffusion from reaction volume;

$\mathrm{k}_{\mathrm{rec}}=\mathrm{OH}$ recombination;

$\mathrm{k}_{\mathrm{ic}}=\mathrm{OH}$ reaction with impurities in the carrier gas;

$\mathrm{k}_{\mathrm{ir}}=\mathrm{OH}$ reaction with impurities in the reactant;

$\mathrm{k}_{\text {ORGANIC }}=\mathrm{OH}$ reaction with organic reactant;

${ }^{2}$ The molar extinction coefficient, $\varepsilon$, for $\mathrm{N}_{2} \mathrm{O}$ photolysis, and the quantum yield, $\phi$, for $\mathrm{O}\left({ }^{1} \mathrm{D}\right)$ atom production from $\mathrm{N}_{2} \mathrm{O}$ photolysis with $193 \mathrm{~nm}$ radiation was taken from the literature. $\mathrm{P} / \mathrm{A}$ is defined as the laser power (watts) divided by the cross-sectional area $\left(\mathrm{cm}^{2}\right)$. 
$\mathrm{k}_{\mathrm{tr}}=\mathrm{OH}$ reaction with thermal radical produced by $\mathrm{k}_{\text {ORGANIC reaction; }}$

$\mathrm{k}_{\mathrm{pr}}=\mathrm{OH}$ reaction with photolytic fragment derived from organic reactant photolysis;

$\mathrm{k}_{\mathrm{sec}}=\mathrm{OH}$ reaction with stable molecule produced by a sequence of photolytic or thermally-induced secondary reactions.

In the absence of photolytically and thermally generated secondary reactions, reactive and diffusive $\mathrm{OH}$ decay profiles exhibit exponential behavior and are fit by the following non-linear expression:

$$
[\mathrm{OH}]=[\mathrm{OH}]_{0} \exp \left(-\mathrm{k}^{\prime} \mathrm{t}\right)+\gamma
$$

where $\gamma=$ background (constant) signal level. Because $[\mathrm{OH}] \ll$ [organic] in all reactive experiments, exponential "reaction only" $[\mathrm{OH}]$ dependences, of pseudo-first-order decay constant $\mathrm{k}^{\prime}=\mathrm{k}_{\text {organic }}$ [organic] are expected. Bimolecular rate coefficients are obtained from the slope of the least-squares straight line through the ([organic, $k^{\prime}$ ) data points.

Inspection of eqn. 2 indicates that the first three terms, i.e., $\mathrm{k}_{\mathrm{dif}}, \mathrm{k}_{\mathrm{rec}}$, and $\mathrm{k}_{\mathrm{ic}}$, are independent of the substrate concentration. Our previous studies have shown strictly linear $\mathrm{OH}$ decay plots, indicating the insignificance of the second term. The magnitude of the remaining terms are summed in the y-intercept of plots of pseudo-first-order rate coefficients versus substrate concentration. Our experiments indicate that this first-order decay in the absence of reactant is relatively constant $\left(200 \pm 50 \mathrm{~s}^{-1}\right)$ and independent of temperature.

The remaining terms in eqn. 2 are dependent on the substrate concentration and, in principle, may all contribute to the measured bimolecular rate constant. Extensive purification of all reactants followed by GC-MS analysis is conducted to evaluate the effect of $k_{i s}$ on the measured bimolecular rate constant. To a first approximation, it is expected that $k_{t r}, k_{p r}$, and $k_{s e c}$ will be negligible in their contribution to the measured rate because our experiments are conducted under single reaction, slow-flow conditions. Thus, reactive fragments or molecules potentially produced by a variety of processes are swept out of the reaction volume before having an opportunity to react and cause a change in the measured rate. If important, the terms involving reaction with the photolytically generated radical and olefin manifest themselves by generating a non-linear dependence of the $\mathrm{OH}$ disappearance rate on the $193.3 \mathrm{~nm}$ photolysis beam intensity. We test for possible substrate photolysis effects on measurements of $\mathrm{k}_{\text {organic }}$ by varying the photolysis intensity. The production of reactive stable species derived from reactant photolysis, i.e., $\mathrm{k}_{\mathrm{sec}}$, are not expected to impact rate measurements at low photolysis intensities. Furthermore, secondary thermal reactions involving olefinic intermediates are not expected to complicate our measurements due to the low initial $\mathrm{OH}$ concentrations employed.

\section{Results}

We have initially focused on rate measurements for methanol and ethanol. This was done for two reasons. The first reason was to verify that our experimental technique could be applied to oxygenated compounds. Our previous studies have been limited to chlorinated hydrocarbons. ${ }^{10-12}$ The second reason was to verify the dominant reaction channels for the oxidation of these altemative fuels. Reliable rate data for methanol and ethanol have been previously obtained from room temperature up to temperatures of $\sim 800 \mathrm{~K} .13$ The studies of Hess and Tully have been the most comprehensive and are considered the most accurate. ${ }^{14,15}$ Comparison of our results with the previous results of Hess and Tully will be used to validate our approach.

We have obtained rate coefficients for the reaction of hydroxyl radicals with methanol spanning a temperature range of 298 to $900 \mathrm{~K}$. The results are presented in Arrhenius form in Fig. 
26. The error bars $(1 \sigma)$ associated with our measurements are based on a propagation of error analysis. The experimental results are in excellent quantitative agreement with the recent measurements of Hess and Tully ${ }^{14}$ and the Arrhenius recommendation of Atkinson. ${ }^{13}$ Above 900 $\mathrm{K}$, plots of observed first-order rate constant versus methanol concentration did not produce meaningful correlations. We attribute this to the thermal decomposition of methanol. The observed onset of thermal decomposition $(-925-950 \mathrm{~K})$ is consistent with the flow reactor studies reported in Task 1.

Our rate measurements for methanol $+\mathrm{OH}$ support the mechanistic discussion described by Hess and Tully 14 and Atkinson. 13 The reaction of the $\mathrm{OH}$ radicals with methanol proceeds by $\mathrm{H}$ atom abstraction, from either the -- $\mathrm{CH}_{3}$ group or the - $\mathrm{OH}$ group, as shown below:

$$
\begin{aligned}
& \mathrm{CH}_{3} \mathrm{OH}+\mathrm{OH} \longrightarrow \mathrm{CH}_{2} \mathrm{OH}+\mathrm{HOH} \\
& \mathrm{CH}_{3} \mathrm{OH}+\mathrm{OH} \longrightarrow-->\mathrm{CH}_{3}+\mathrm{HOH} .
\end{aligned}
$$

Based upon the $\mathrm{C}-\mathrm{H}$ and $\mathrm{O}-\mathrm{H}$ bond dissociation enthalpies of 94.1 and $104.5 \mathrm{kcal} \mathrm{mol}^{-1}$, respectively ${ }^{16}$, reaction pathway $1 \mathrm{a}$ would be expected to dominate at room temperature. Hess and Tully have conducted deuterium isotope studies of this reaction $\left(\mathrm{CH}_{3} \mathrm{OH}+\mathrm{OH}\right.$ vs. $\left.\mathrm{CD}_{3} \mathrm{OH}+\mathrm{OH}\right)$ over a temperature range of 294 to $861 \mathrm{~K}$. They observed a significant deuterium isotope effect over the entire temperature range thus indicating that reaction la dominates even at temperatures approaching $900 \mathrm{~K}$.

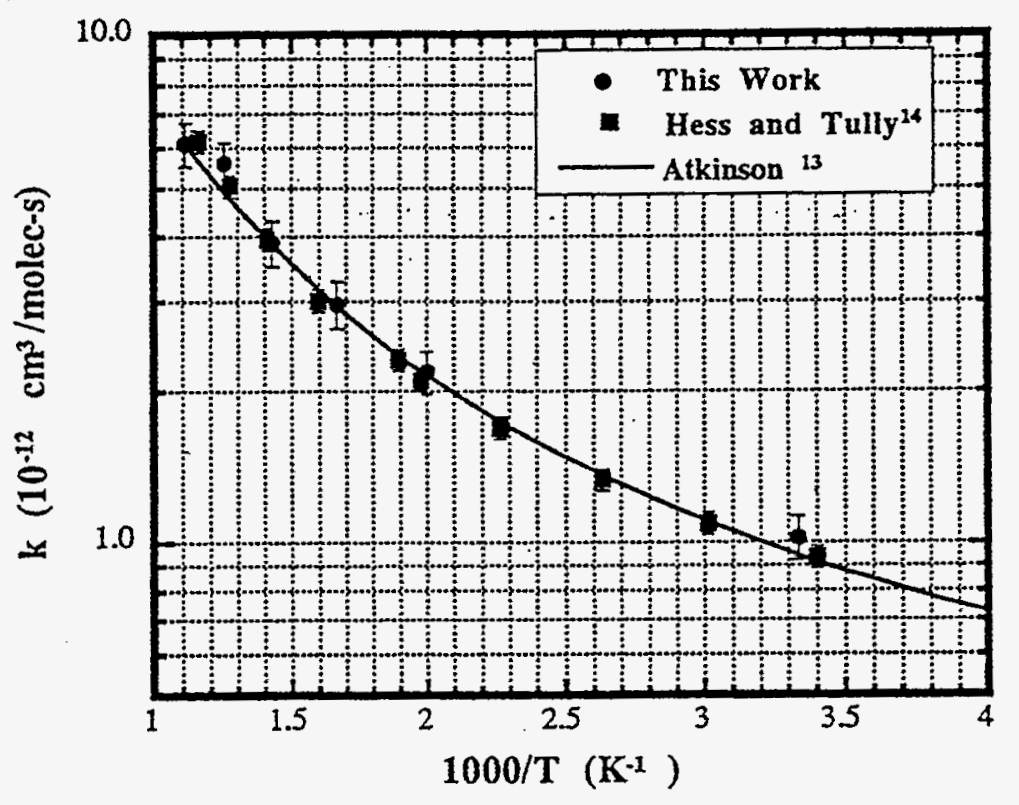

Figure 26. Arrhenius plot of the reaction of $\mathrm{OH}$ with methanol. Also shown are previous studies of Hess and Tully 14 and the recommended Arrhenius prediction of Atkinson. 13

We have also obtained rate coefficients for the reaction of hydroxyl radicals with ethanol spanning a temperature range of 298 to $800 \mathrm{~K}$. The results are presented in Arhenius form in Fig. 27. The error bars $(1 \sigma)$ associated with our measurements are based on a propagation of error analysis. In this case, the experimental results above $500 \mathrm{~K}$ shown some deviation from the recent 
measurements of Hess and Tully ${ }^{15}$ and the recommendation of Atkinson. ${ }^{13}$ Above $800 \mathrm{~K}$, plots of observed first-order rate constant versus ethanol concentration did not produce meaningful comelations. We attribute this to the thermal decomposition of ethanol.

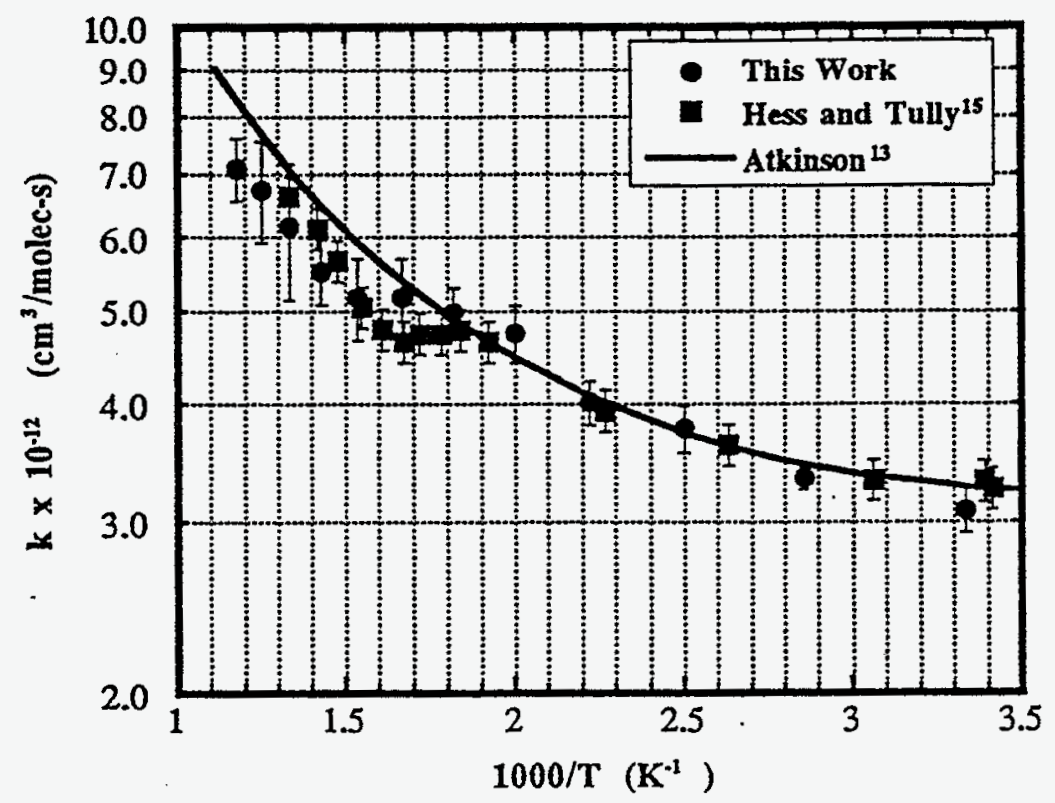

Figure 27. Arrhenius plot of the reaction of $\mathrm{OH}$ with ethanol. Also shown are previous studies of Hess and Tully ${ }^{15}$ and the recommended Arrhenius prediction of Atkinson. ${ }^{13}$

The reaction of the $\mathrm{OH}$ radicals with ethanol proceeds by $\mathrm{H}$ atom abstraction, from either the -- $\mathrm{CH}_{3}$ group, the -- $\mathrm{CH}_{2}$ group, or the --OH group, as shown below:

$$
\begin{aligned}
& \mathrm{CH}_{3} \mathrm{CH}_{2} \mathrm{OH}+\mathrm{OH}<-\cdots>\mathrm{CH}_{2} \mathrm{CH}_{2} \mathrm{OH}+\mathrm{HOH} \\
& \mathrm{CH}_{3} \mathrm{CH}_{2} \mathrm{OH}+\mathrm{OH}<-\cdots>\mathrm{CH}_{3} \mathrm{CHOH}+\mathrm{HOH} . \\
& \mathrm{CH}_{3} \mathrm{CH}_{2} \mathrm{OH}+\mathrm{OH}<-\cdots>\mathrm{CH}_{3} \mathrm{CH}_{2} \mathrm{O}+\mathrm{HOH} .
\end{aligned}
$$

The $\mathrm{CH}_{2} \mathrm{CH}_{2} \mathrm{OH}$ radical formed in pathway $2 \mathrm{a}$ is identical to that formed from the addition of the $\mathrm{OH}$ radical to ethylene. Tully has previously shown that the thermalized $\mathrm{CH}_{2} \mathrm{CH}_{2} \mathrm{OH}$ radical decomposes to the $\mathrm{OH}$ radical and ethylene at a significant rate above $\sim 450$ to $500 \mathrm{~K}$. 17 This result suggests that in absolute studies employing $16 \mathrm{OH}$ and $16 \mathrm{O}$-ethanol, measurements below $\sim 450$ to $500 \mathrm{~K}$ result in $k_{\text {obs }}=k_{2 a}+k_{2 b}+k_{2 c}$ while for temperatures above $500 \mathrm{~K}, k_{0 b s}=k_{2 b}+k_{2 c}$. In a recent study, Hess and Tully 15 confirmed this expectation. As shown in Fig. 2 , the measured rate coefficients for the reaction of $16 \mathrm{OH}$ with ethanol exhibit a plateau region at $\sim 520$ to $600 \mathrm{~K}$. Furthermore, a measurement of the rate constant for ${ }^{18} \mathrm{OH}$ with ethanol, which is not subject to regeneration of the ${ }^{18} \mathrm{OH}$ radical from the thermal decomposition of the $\mathrm{CH}_{2} \mathrm{CH}_{2} 16 \mathrm{OH}$ radical formed in pathway $2 \mathrm{a}$, at $600 \mathrm{~K}$ was $\sim 15 \%$ higher than that measured for the $16 \mathrm{OH}$ reaction. These data indicated that pathway $2 a$ accounts for $-15 \%$ of the overall reaction at $-600 \mathrm{~K}$.

Our measurements of the reaction of $16 \mathrm{OH}$ with ethanol do not show a plateau region of reactivity between 520 and $600 \mathrm{~K}$. For our experimental conditions, we observed reduced reactivity between $600-700 \mathrm{~K}$. Although shifted slightly to higher temperatures, our results 
nonetheless support the contention of Hess and Tully that pathway 2a becomes significant at relatively low temperatures. At $750 \mathrm{~K}$ (and above), our results once again agree with the previous measurements. Taking into account pathway $2 \mathrm{a}$ and assuming this pathway contributes $\sim 20-30 \%$ to the overall rate, we conclude that the recommended modified Arrhenius expression of Atkinson $(n=2)$ extrapolated to higher temperatures is consistent with our measurements and should be used to represent this important reaction in kinetic models of ethanol combustion.

\section{Discussion}

The hydroxyl reactivity studies for methanol and ethanol are remarkably consistent with the thermal oxidative degradation studies reported in Task 1 . As discussed below, the results demonstrate the importance of $\mathrm{H}$ abstraction reactions as both initiation steps and intermediate . conversion steps to the formation of the primary air pollutants observed for both of these alternative fuels.

For methanol, two $\mathrm{H}$ abstraction reaction channels are possible. Deuterium isotope studies by Hess and Tully ${ }^{14}$ indicated that $\mathrm{H}$ abstraction $\alpha$ to the hydroxy group dominates up to temperatures of $900 \mathrm{~K}$. Our experimental studies over an extended temperature range do not show any evidence to the contrary. As a result, H abstraction from the hydroxy group is not expected to be significant below temperatures of $1000 \mathrm{~K}$.

Figure 28 presents a reaction pathway diagram for methanol oxidation that is consistent with our flow reactor and $\mathrm{OH}$ radical measurements. Hydroxymethyl radicals $\left(\mathrm{CH}_{2} \mathrm{OH}\right)$ are the primary intermediates formed following $\mathrm{H}$ abstraction from methanol. $\mathrm{CH}_{2} \mathrm{OH}$ is then converted to formaldehyde $(\mathrm{HCHO})$ via a $\mathrm{H}$ elimination process. Recent kinetic studies indicate that $\mathrm{H}$ abstraction is the dominant mechanism above $500 \mathrm{~K} .18 \mathrm{HCHO}$ is then converted to formyl radicals ( $\mathrm{HCO}$ ) via another $\mathrm{H}$ abstraction channel. ${ }^{19}$ The kinetics of conversion of $\mathrm{HCO}$ to $\mathrm{CO}$ to $\mathrm{CO}_{2}$ is comparably well understood. The observation of $\mathrm{HCHO}$ as the primary reaction byproduct from the intermediate temperature ( $673 \mathrm{~K}$ to $973 \mathrm{~K}$ ) oxidation of methanol is consistent with this analysis. At elevated temperatures $(>900 \mathrm{~K})$, a secondairy intermediate, methoxy radical $\left(\mathrm{CH}_{3} \mathrm{O}\right)$ will also form via $\mathrm{H}$ abstraction from the hydroxy group. The role of methoxy radicals in methane oxidation remains unresolved. Reactions of methyl radicals with $\mathrm{O}$ atoms result in rapid formation of HCHO. Under sub-stoichiometric conditions, dissociation of methoxy radicals into methyl radicals and $O$ atoms may also occur. The formation of methyl radicals and their subsequent recombination and dissociation lead to the formation of ethane and ethene. Methane, ethane and ethene were the only organic reaction byproducts observed from the stoichiometric and substoichiometric oxidation of methanol at high temperatures (1323 K). 


\section{$\mathrm{CH}_{3} \mathrm{OH}$}
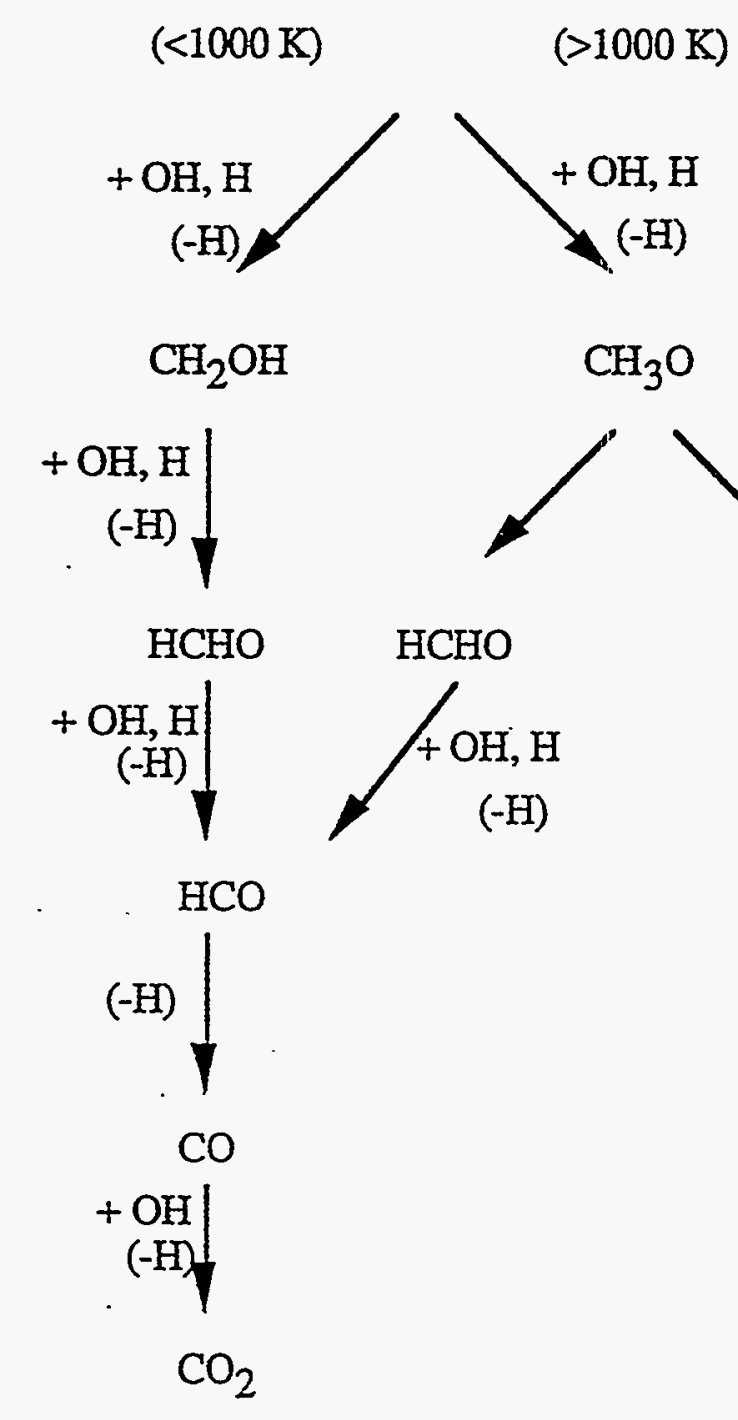

$\mathrm{CH}_{3} \mathrm{O}$
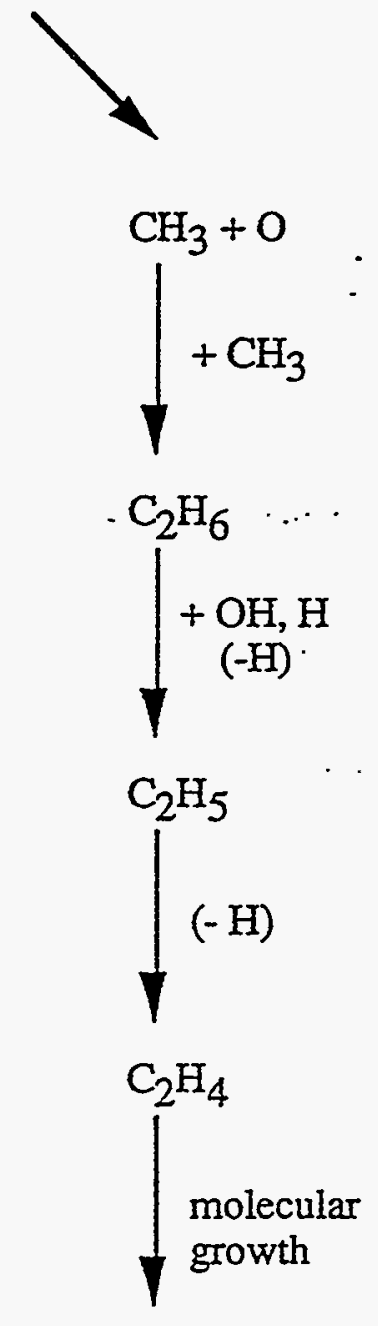

larger hydrocarbons

Figure 28. Reaction pathway diagram for methanol oxidation.

For ethanol, three $\mathrm{H}$ abstraction reaction channels are possible. Nuclear isotope studies ( ${ }^{16} \mathrm{OH}$ and ${ }^{18} \mathrm{OH}$ ) by Hess and Tully 15 indicated that $\mathrm{H}$ abstraction $\alpha$ to the hydroxy group dominates up to temperatures of $525 \mathrm{~K}$. At higher temperatures $(525-800 \mathrm{~K}), \mathrm{H}$ abstraction $\beta$ to the hydroxy group became significant. Our experimental studies over a similar temperature range generally supports their analysis, although our studies indicate that $\mathrm{H}$ abstraction $\beta$ to the hydroxy 
group becomes significant at slightly higher temperatures $(>600 \mathrm{~K})$. H abstraction from the hydroxy group is not expected to be significant below temperatures of $1000 \mathrm{~K}$.

Figure 29 presents a reaction pathway diagram for ethanol oxidation that is consistent with our flow reactor and $\mathrm{OH}$ radical measurements. The availability of three $\mathrm{H}$ abstraction reaction channels results in the oxidation of ethanol being somewhat more complex than methanol. At temperatures below $600 \mathrm{~K}, \mathrm{H}$ abstraction results in the formation of $\mathrm{CH}_{3} \mathrm{CHOH}$ radicals. $\mathrm{CH}_{3} \mathrm{CHOH}$ are then converted to acetaldehyde $\left(\mathrm{CH}_{3} \mathrm{CHO}\right)$ via a $\mathrm{H}$ elimination process. The actual reaction channels involved, which include $\mathrm{H}$ abstraction or $\mathrm{H}$ loss via radical decomposition followed by rearrangement, have not been clearly elucidated. By analogy with methanol, we may infer that $\mathrm{H}$ abstraction is the dominant channel above $500 \mathrm{~K}$. $\mathrm{CH}_{3} \mathrm{CHO}$ is then converted to acetyl radicals $\left(\mathrm{CH}_{3} \mathrm{CO}\right)$ via a $\mathrm{H}$ abstraction channel. Recent kinetic studies indicate that acetyl radicals rapidly decompose to $\mathrm{CH}_{3}$ and $\mathrm{CO}$ at relatively modest temperatures. ${ }^{20}$ The observation of $\mathrm{CH}_{3} \mathrm{CHO}$ as the primary reaction byproduct from the oxidation of ethanol below $673 \mathrm{~K}$ is consistent with this analysis. At slightly higher temperatures, a secondary intermediate, $\mathrm{CH}_{2} \mathrm{CH}_{2} \mathrm{OH}$ radical will also form via $\mathrm{H}$ abstraction $\beta$ to the hydroxy group. Our results suggest that this intermediate rapidly decomposes to $\mathrm{OH}$ and ethene at temperatures above $600 \mathrm{~K}$. The formation of $\mathrm{CH}_{3}$ radicals from $\mathrm{H}$ abstraction $\alpha$ to the hydroxy group and the formation of ethene from the $\mathrm{H}$ abstraction channel $\beta$ to the hydroxy group are consistent with the observed organic byproducts observed from ethanol oxidation at higher temperatures $(>673 \mathrm{~K})$, i.e., ethene, ethane, acetylene, and methane. Under fuel-rich conditions, the rapid formation of ethene appears to be the key precursor to hydrocarbon molecular growth and the formation of benzene. At very high temperatures $(>1000 \mathrm{~K})$, another secondary intermediate, ethoxy $\left(\mathrm{CH}_{3} \mathrm{CH}_{2} \mathrm{O}\right)$ radicals will also form via $\mathrm{H}$ abstraction from the hydroxy group. Ethoxy radicals will readily decompose at these high temperatures forming methyl radicals and formaldehyde. Formaldehyde is not stable at these temperatures and will rapidly decompose and further oxidize to $\mathrm{CO}$ and $\mathrm{CO}_{2}$. The formation of methyl radicals will, under sub-stoichiometric oxidation conditions, through their subsequent -recombination and dissociation lead to the formation of ethane and ethene. This represents a higher temperature pathway to the formation of $\mathrm{C}_{1}$ and $\mathrm{C}_{2}$ hydrocarbons observed in the high-temperature oxidation of ethanol. 


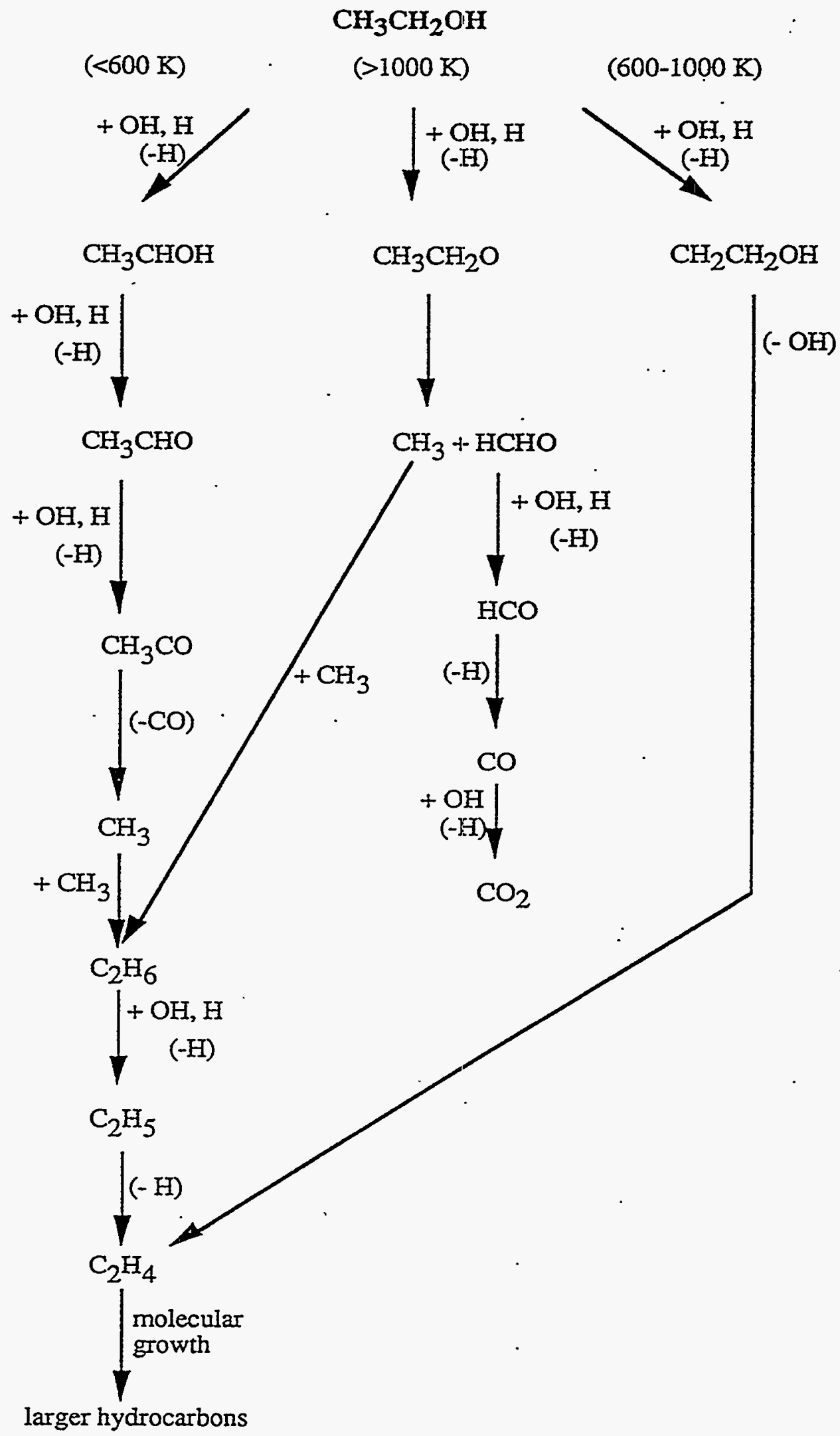

Figure 29. Reaction pathway diagram for ethanol oxidation. 


\section{References}

1. S. Shanbhag, 1995, "Combustion Byproducts of Alternative Automotive Fuels," M.S. Thesis, University of Dayton.

2. K. Whitney, 1994, "Determination of Alternative Fuels Combustion Products," Draft Final Report prepared for the National Renewable Energy Laboratory.

3. P. H. Taylor and B. Dellinger, 1994, "Impacts of Alternative Fuels on Air Quality," NREL/TP-425-6650, Golden, CO: National Renewable Energy Laboratory.

4. P. H. Taylor, S. Shanbhag, and B. Dellinger, 1994, SAE Technical Paper Series No. 941904, Warrendale, $\mathrm{PA}$.

5. W. K. Cheng, D. Hamrin, J. B. Heywood, S. Hochgreb, K. Min, and M. Norris, 1993, SAE Technical Paper Series No. 932708, Warrendale, PA.

6. K. Drobot, W. K. Cheng, F. H. Trinker, E. W. Kaiser, W. O. Siegl, D. F. Cötton, and J. Underwood, 1994, Combustion and Flame, Vol. 99, pp. 422-430.

7. E. W. Kaiser, 1994, SAE Technical Paper Series No. 941960 , Warrendale, PA.

8. J. D. Pakko, A. A. Adamczyk, W. O. Siegl, and R. J. Pawlowicz, 1994, SAE Technical Paper Series No. 941999, Warrendale, PA.

9. H. Tsuchida, K. Ishihara, Y. Iwakiri, and M. Matsumoto, 1993, SAE Technical Paper Series No. 932718, Warrendale, PA.

10. P. H. Taylor, M. C. Martin, J. H. Kasner, J. A. D'Angelo, and B. Dellinger, 1989, Int. J. Chem. Kinet., Vol. 21, pp. 829-846.

11. J. H. Kasner, P. H. Taylor, and B. Dellinger, 1990, J. Phys. Chem., Vol. 94, pp. 32503252.

12. Z. Jiang, P. H. Taylor, and B. Dellinger, 1992, J. Phys. Chem., Vol. 96, pp. 8964-8966.

13. R. Atkinson, 1990, J. Phys. Chem. Ref. Data, Monograph 1.

14. W. P. Hess and F. P. Tully, 1988, Chem. Phys. Lett., Vol. 152, pp. 183.

15. W. P. Hess and F. P. Tully, 1989, J. Phys. Chem., Vol. 93, pp. 1944.

16. R. Atkinson, D. L. Baulch, R. A. Cox, R. F. Hampson, Jr., J. A. Kerr, and J. Troe, 1989, J. Phys. Chem. Ref. Data, Vol. 18, pp. 881.

17. F. P. Tully, 1988, Chem. Phys. Lett., Vol. 143, pp. 510.

18. H.-H. Grotheer, G. Riekert, D. Walter, and T. Just, 1988, J. Phys. Chem., Vol. 92, pp. 4028-4030.

19. J. Warnatz, 1992, Twenty-Fifth Symp. (Int.) on Combust., The Combustion Institute, pp. 553-579.

20. A. Bencsura et al., 1992, Ber. Bunsenges. Phys. Chem.; Vol. 96, pp. 1338-1347. 


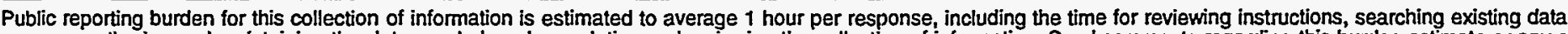

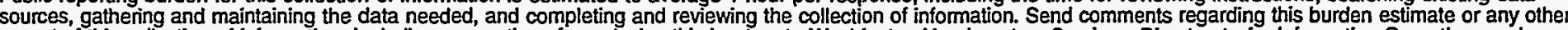

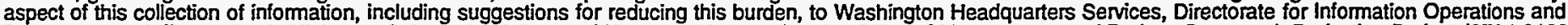

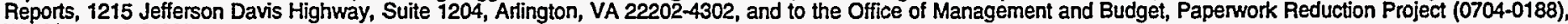
Washington, DC 20503.
1. AGENCY USE ONLY (Leave blank)

\section{REPORT DATE \\ June 1995}
3. FIEPORT TYPE AND DATES COVERED Subcontract report

\section{TITLE AND SUBTITLE}

The Origin and Fate of Organic Pollutants from the Combustion of Alternative Fuels

$$
\text { 6. AUTHOR(S) }
$$

University of Dayton Research Institute

\section{PERFORMING ORGANIZATION NAME(S) AND ADDRESS(ES)}

University of Dayton Research Institute

300 College Park Avenue

Dayton, $\mathrm{OH} \quad 45469-0132$

\section{SPONSORING/MONITORING AGENCY NAME(S) AND ADDRESS(ES)}

National Renewable Energy Laboratory

1617 Cole Boulevard

Golden, CO $80401-3393$

\section{SUPPLEMENTARY NOTES}

\section{2a. DISTRIBUTION/AVAILABILITY STATEMENT}

National Technical Information Service

U.S. Department of Commerce

5285 Port Royal Road

Springfield, VA 22161
5. FUNDING NUMBERS

(C) XAU-3-12228-02

(TA) FU521010

8. PERFORMING ORGANIZATION REPORT NUMBER

DE95009232

10. SPONSORING/MONITORING AGENCY REPORT NUMBER

NRELTP-425-7607

\section{ABSTRACT (Maximum 200 words)}

The objective of this project is to determine the impact of alternative fuels on air quality, particularly ozone formation. The objective will be met through three steps: qualitative identification of altemative fuel combustion products, 2) quantitative measurement of specific emissions levels of these products, and 3) determination of the fate of the combustion products in the atmosphere. The alternative fuels being examined are methanol, ethanol, natural gas, and LP gas. This report presents the results of the second phase of the study.

\section{SUBJECT TERMS}

Altemative fuels, air quality, emissions, ozone formation 35

16. PRICE CODE

\section{SECURITY CLASSIFICATION} OF REPORT
18. SECURITY CLASSIFICATION OF THIS PAGE
19. SECURITY CLASSIFICATION OF ABSTRACT

\section{2b. DISTRIBUTION CODE}

UC 1504 